\title{
Mitochondrial replacement in human oocytes carrying pathogenic mitochondrial DNA mutations
}

\author{
Eunju Kang ${ }^{1,2} \dagger$, Jun $\mathrm{Wu}^{3}$, Nuria Marti Gutierrez ${ }^{1,2}$, Amy Koski ${ }^{1,2}$, Rebecca Tippner-Hedges ${ }^{1,2}$, Karen Agaronyan ${ }^{4}$, \\ Aida Platero-Luengo ${ }^{3}$, Paloma Martinez-Redondo ${ }^{3}$, Hong Ma ${ }^{1,2}$, Yeonmi Lee ${ }^{1,2} \uparrow$, Tomonari Hayama ${ }^{1,2}$, Crystal Van Dyken ${ }^{1,2}$, \\ Xinjian Wang ${ }^{5}$, Shiyu Luo $^{5}$, Riffat Ahmed ${ }^{1,2}$, Ying Li $^{1,2}$, Dongmei Ji ${ }^{1,6}$, Refik Kayali ${ }^{7}$, Cengiz Cinnioglu ${ }^{7}$, Susan Olson ${ }^{8}$, \\ Jeffrey Jensen ${ }^{9}$, David Battaglia ${ }^{9}$, David Lee ${ }^{9}$, Diana $\mathrm{Wu}^{9}$, Taosheng Huang ${ }^{5}$, Don P. Wolf ${ }^{1,2}$, Dmitry Temiakov ${ }^{4}$, \\ Juan Carlos Izpisua Belmonte ${ }^{3}$, Paula Amato ${ }^{9}$ \& Shoukhrat Mitalipov $^{1,2,9,10,11}$
}

\begin{abstract}
Maternally inherited mitochondrial (mt)DNA mutations can cause fatal or severely debilitating syndromes in children ${ }^{1-3}$, with disease severity dependent on the specific gene mutation and the ratio of mutant to wild-type mtDNA (heteroplasmy) in each cell and tissue ${ }^{4}$. Pathogenic mtDNA mutations are relatively common, with an estimated 778 affected children born each year in the United States $^{5}$. Mitochondrial replacement therapies or techniques (MRT) circumventing mother-to-child mtDNA disease transmission involve replacement of oocyte maternal mtDNA ${ }^{6-8}$. Here we report MRT outcomes in several families with common mtDNA syndromes. The mother's oocytes were of normal quality and mutation levels correlated with those in existing children. Efficient replacement of oocyte mutant mtDNA was performed by spindle transfer ${ }^{8}$, resulting in embryos containing $>\mathbf{9 9} \%$ donor mtDNA. Donor mtDNA was stably maintained in embryonic stem cells (ES cells) derived from most embryos. However, some ES cell lines demonstrated gradual loss of donor mtDNA and reversal to the maternal haplotype. In evaluating donor-to-maternal mtDNA interactions, it seems that compatibility relates to mtDNA replication efficiency rather than to mismatch or oxidative phosphorylation dysfunction. We identify a polymorphism within the conserved sequence box II region of the D-loop as a plausible cause of preferential replication of specific mtDNA haplotypes. In addition, some haplotypes confer proliferative and growth advantages to cells. Hence, we propose a matching paradigm for selecting compatible donor mtDNA for MRT.
\end{abstract}

Because mitochondrial disease can be attributed to gene mutations in mtDNA and/or nuclear DNA ${ }^{9}$, an important clinical challenge is to first confirm pathogenic mtDNA mutations in families eligible for MRT. We recruited four families diagnosed with Leigh syndrome and one with MELAS (mitochondrial encephalomyopathy with lactic acidosis and stroke-like episodes) and conducted genetic testing to confirm maternal inheritance (Extended Data Fig. 1a). We collected DNA from blood, skin fibroblasts and/or urine from children and mothers, and performed whole mtDNA sequencing. The first Leigh syndrome family had an affected 2-year-old child with a homoplasmic T8993G substitution encoding the ATPase 6 gene (MT-ATP) of mtDNA in both blood and skin fibroblast samples while her 22-year-old mother had the same mutation with 70\% heteroplasmy in blood and $100 \%$ in skin fibroblasts (Fig. 1a, left). In the second related Leigh syndrome family, an affected 2.5-year-old child carried the same T8993G mutation at 95\% heteroplasmy in blood and $100 \%$ in skin fibroblasts, while in a second 1 -year-old asymptomatic sibling, the mutation load was $50 \%$ in blood and $62 \%$ in skin fibroblasts. Their 23 -year-old mother, who is the elder sister of the subject from the first family, carried this mutation at 13\% in blood and $16 \%$ in skin fibroblasts (Fig. 1a, left). In the third Leigh syndrome family, the affected 12-year-old boy had a G13513A substitution affecting the MT-ND5 gene at 56\%, 86\% and 97\% heteroplasmy in blood, skin fibroblasts and urine, respectively. His asymptomatic 19-year-old brother carried the same mutation at 10\%, 14\% and 23\% heteroplasmy levels in blood, skin fibroblasts and urine, respectively. Their 36-year-old mother also harboured the mutation at 3\%, 98\% and $39 \%$ levels in blood, skin fibroblasts and urine, respectively (Fig. 1a, middle). A fourth family presented with a 1-year-old child diagnosed with Leigh syndrome. However, genetic screening did not reveal any pathogenic mtDNA mutations in the child or mother. The last family was from a large, well-studied MELAS pedigree carrying a pathogenic A3243G mutation in the MT-TL1 encoding tRNA leucine ${ }^{10}$ (Extended Data Fig. 1b). The 32-year-old mother carried the mutation at $14 \%$, $47 \%$ and $35 \%$ in blood, skin fibroblasts and urine, respectively. All three of her children inherited this mutation (Fig. 1a, right). Thus, pathogenic mtDNA mutations were implicated in four of the five families, highlighting the importance of genetic testing for maternally inherited mtDNA diseases before MRT. Moreover, because heteroplasmy levels may vary among different tissues, it is critical to sample and test blood, skin and urine, in both mothers and children ${ }^{11}$.

We also screened 11 healthy volunteer oocyte donors and confirmed that they did not carry inherited pathogenic mtDNA mutations. The mtDNA sequences and corresponding haplotypes were used for matched MRT combinations (Supplementary Table 1).

Women with mtDNA disease display live birth rates comparable to the general population ${ }^{5}$, suggesting normal fertility. We studied ovarian response to gonadotropin stimulation and oocyte recovery in women carrying pathogenic mtDNA mutations (carriers). Anti-Müllerian hormone levels, a measure of ovarian reserve, were lower in carriers than in healthy donors ( 1.1 compared to $\left.4.8 \mathrm{ng} \mathrm{ml}^{-1}\right)$. Antral follicle count (AFC) was also lower in carriers compared to the healthy donors (10.3 compared to 22.3). In addition, the duration of controlled ovarian stimulation was about one day longer in the carriers and their peak blood oestradiol (E2) level before human chorionic gonadotropin (hCG) administration also trended lower. Finally, the total number of oocytes and the number of mature metaphase II oocytes retrieved were

\footnotetext{
${ }^{1}$ Center for Embryonic Cell and Gene Therapy, Oregon Health \& Science University, 3303 SW Bond Avenue, Portland, Oregon 97239, USA. ${ }^{2}$ Division of Reproductive \& Developmental Sciences,

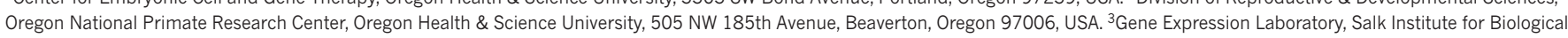
Studies, 10010 North Torrey Pines Road, La Jolla, California 92037, USA. ${ }^{4}$ Department of Cell Biology School of Osteopathic Medicine, Rowan University, 2 Medical Center Drive, Stratford, New Jersey 08084, USA. ${ }^{5}$ Division of Human Genetics, Cincinnati Children's Hospital Medical Center, 3333 Burnet Avenue, Cincinnati, Ohio 45229, USA. ${ }^{6}$ Reproductive Medical Centre, Anhui

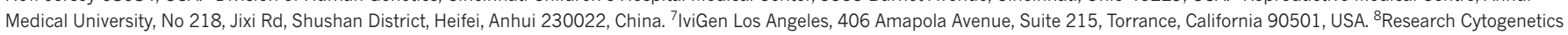
Laboratory, Oregon Health \& Science University, 3181 SW Sam Jackson Park Road, Portland, Oregon 97239, USA. ${ }^{9}$ Division of Reproductive Endocrinology, Department of Obstetrics and Gynecology, Oregon Health \& Science University, 3303 SW Bond Avenue, Portland, Oregon 97239, USA. ${ }^{10}$ Knight Cardiovascular Institute, Oregon Health \& Science University, 3181 SW Sam Jackson Park Road, Portland, Oregon 97239, USA. ${ }^{11}$ Department of Biomedical Engineering, Oregon Health \& Science University, 3303 SW Bond Avenue, Portland, Oregon 97239, USA. $\nmid$ Present address: Stem Cell Center, ASAN Institute for Life Sciences, ASAN Medical Center, Olympic-ro 43-gil, Songpa-gu, Seoul 138-736, South Korea.
} 
a
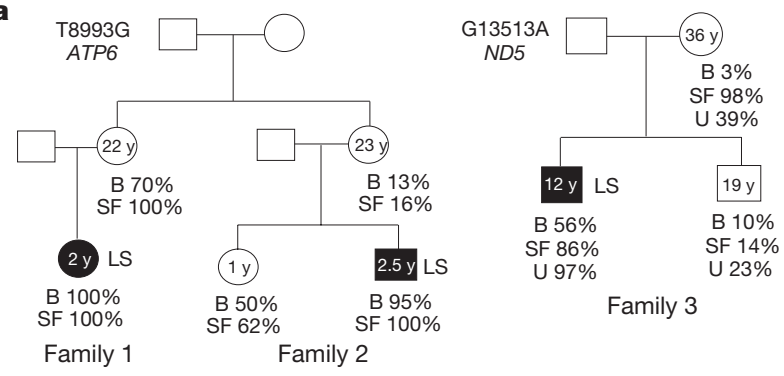

b

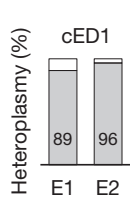

cED2

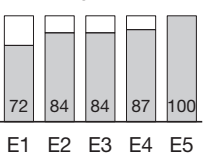

LS: T8993G

c

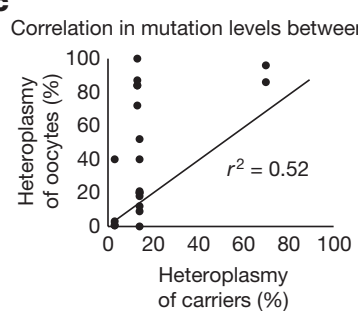

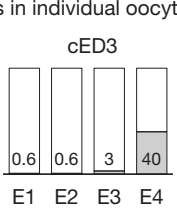

LS: G13513A

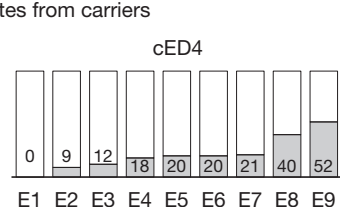

MELAS: A3243G

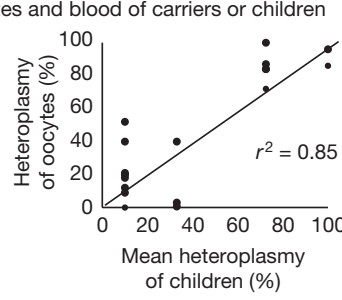

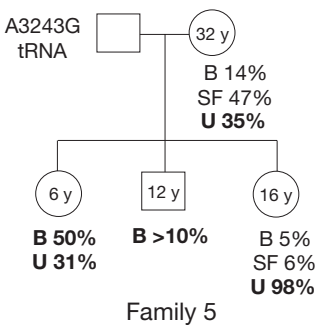

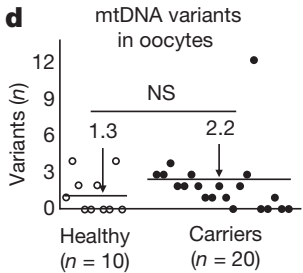

e

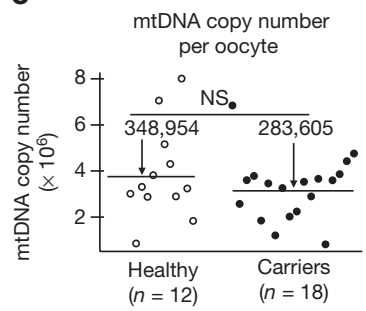

Figure 1 | Characteristics of families and retrieved oocytes in women carrying pathogenic mtDNA mutations (carriers) or wild-type mtDNA (healthy). a, Somatic tissue heteroplasmy levels in families (see also Extended Data Fig. 1b). Heteroplasmy levels obtained from previous reports ${ }^{10}$ are shown in bold. In all families, the heteroplasmy levels for mtDNA mutations were diverse among tissues and individuals, and associated with clinical disease. See also Supplementary Table 2. Black filled, diagnosed with a mitochondrial disease. LS, Leigh syndrome. y, years-old. Square, male; circle, female. B, blood; SF, skin fibroblasts; $\mathrm{U}$, urine. b. Individual oocytes harboured different heteroplasmy levels. cED, carrier egg donor. c, The mean heteroplasmy in oocytes correlated

also lower in carriers (5.8 versus 16.6 and 3.8 versus 13.2, respectively) (Extended Data Fig. 2a-g). Of note, one carrier (cED 2) exhibited premature luteinization, as evidenced by increased progesterone levels before hCG administration (Extended Data Fig. $2 \mathrm{~h}$ ). Therefore, we only performed mutation analyses on retrieved atretic oocytes. Although the numbers in our cohort were $\operatorname{low}^{12}$, the results suggest that mtDNA mutations could lead to a reduced ovarian response. Older age and a higher body mass index of carriers could also have affected the outcome ${ }^{13,14}$. Another potential contributing factor may be the longterm hormonal contraception these women were on before ovarian stimulation.

After metaphase II spindle (nuclear genome) removal, cytoplasts (mtDNA) were used for sequencing. In the first carrier, two recovered oocytes displayed a T8993G mutation at $89 \%$ and $96 \%$ levels. In the second sibling carrier, heteroplasmy levels in five atretic oocytes ranged from $72 \%$ to $100 \%$. In four oocytes from the third Leigh syndrome carrier, G13513A mutation levels in three eggs were low (0.6-3\%) while the fourth was $40 \%$. Finally, in nine oocytes from the A3243G MELAS carrier, no mutation was detected in one egg while the others carried 9-52\% (Fig. 1b). Mean heteroplasmy levels in the blood of sibling children correlated highly with those in oocytes ${ }^{4,15}\left(r^{2}=0.85\right.$ compared to $r^{2}=0.52$ between mutation levels in the carrier's blood and oocytes, Fig. 1c). Next, we analysed whole mtDNA sequences in carrier oocytes to screen for secondary mtDNA mutations and compared to oocytes from healthy donors. Carrier oocytes contained secondary heteroplasmic mtDNA variants, however the average number per oocyte was not with levels in existing children rather than with maternal levels. Heteroplasmy levels of carriers and children were measured in blood. $r^{2}$, Pearson's $r$ values. d, Comparable mtDNA variants between oocytes with healthy mtDNA and those carrying mutations $(P>0.05)$. e, Mean mtDNA copy number per oocyte in healthy controls was comparable to those carrying pathogenic mtDNA $(P>0.05)$. Karyoplasts were isolated from carrier oocytes for spindle transfer, except oocytes recovered from cED2 who exhibited premature luteinization. Oocytes from healthy egg donors were mature metaphase II. $n$, the number of oocytes; the number in each group is a mean; NS, not significant ( $\mathbf{d}$ and $\mathbf{e}$; analysed by $t$-test). Source data files are available for $\mathbf{c}-\mathbf{e}$.

significantly different from healthy controls ( 2.2 versus $1.3 ; P>0.05)$ (Fig. 1d). Some of these variants were present in several oocytes from the same carrier and were also found in the carrier's blood, skin or in sibling children, suggesting recurring germline mutations. However, these variants were non-coding D-loop mutations (Supplementary Table 2). Others were found only in one oocyte within the group indicative of de novo mutations (45\%). The majority ( $83 \%)$ of these secondary variants were low-level heteroplasmic $(<15 \%)$ mutations (Extended Data Fig. 2i). We also measured mtDNA copy number as an indirect measure of oocyte quality and found no significant differences between healthy and carrier oocytes (mean $=348,954$ compared to 283,605 , respectively) (Fig. 1e). A low mtDNA copy number may play a role in diminished ovarian reserve ${ }^{16}$ but we found no correlation between oocyte copy number and anti-Müllerian hormone levels (Extended Data Fig. 2j).

Meiotic spindles (karyoplasts containing carryover maternal mtDNA) recovered from carrier oocytes $(n=13)$ were transferred into enucleated donor oocytes (cytoplasts; donor mtDNA) (Fig. 2a) while controls involved spindle transfer (ST) between healthy oocytes $(n=36)$ with preselected mtDNA haplotypes (Extended Data Fig. 3a). Spindle transfer oocytes, along with intact (non-manipulated) controls, were then fertilized by intracytoplasmic sperm injection and cultured to blastocysts. High fertilization rates, comparable to controls, were observed in both spindle transfer groups (Fig. 2a and Extended Data Fig. 3b, c). Subsequent development of diploid carrier spindle transfer zygotes to the blastocyst stage was $75 \%$, similar to controls. Similar 

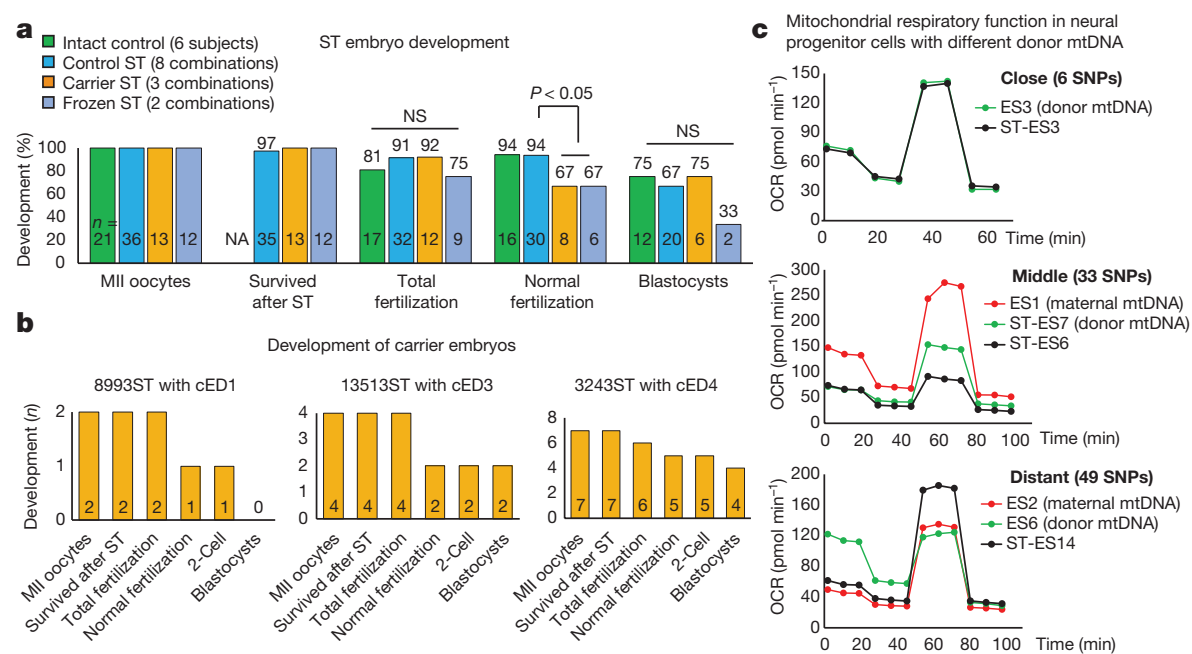

Figure 2 | Spindle transfer outcomes, embryo development and mitochondrial function. a, Spindle transfer (ST) embryo development following various experimental manipulations. Similar developmental outcomes were observed among groups, except normal fertilization, which was significantly lower in carrier and frozen spindle transfer groups $(P<0.05$; one-way ANOVA). Numbers inside bars, number of oocytes or embryos; numbers on the top of bars, percentages. Combinations, mixtures of different mtDNA haplotypes between karyoplast and cytoplast; intact control, unmanipulated embryos, fertilized by intracytoplasmic sperm injection (ICSI). NA, not applicable. b, Carrier spindle transfer embryos

developmental patterns were observed among carriers with different mutation types (8993ST, 13513ST and 3243ST) (Fig. 2b). To address controlled ovarian stimulation asynchrony, we conducted spindle transfer between fresh and vitrified oocytes (frozen spindle transfer). The overall fertilization rate using vitrified oocytes was comparable to fresh spindle transfer, while formation of normal diploid zygotes was reduced (Fig. 2a). No differences in fertilization were noted between combinations involving vitrified karyoplasts versus vitrified cytoplasts (Extended Data Fig. 3d).

Since miscommunication between nuclear and mitochondrial genomes may induce secondary metabolic dysfunction ${ }^{17}$, we analysed spindle transfer embryo development as a function of donor mtDNA sequence distance, as measured indirectly by the number of single nucleotide polymorphism (SNP) differences. Spindle transfer oocytes and embryos were grouped based on the SNP differences between the original (maternal) and donor oocyte mtDNA, ranging from close (6 SNPs) to middle (33 SNPs) to distant (57 SNPs) (Extended Data Fig. 3a and Supplementary Table 1). Fertilization and blastulation rates were similar among all three spindle transfer groups, suggesting that embryo development was not compromised (Extended Data Fig. 3e). Next, we established ES cell lines from spindle transfer blastocysts and differentiated them into neural progenitor cells (NPCs), cardiomyocytes and teratomas. Comparable differentiation efficiencies, mitochondrial respiratory chain enzyme activity and oxygen consumption rates were found between groups (Fig. 2c and Extended Data Fig. 4, 5). Thus, MRT in carrier oocytes supported fertilization and blastocyst development similarly to controls. Also, ES cell derivation and differentiation were unaffected by donor mtDNA genetic backgrounds. However, it is still possible that miscommunication between certain combinations of nuclear and mitochondrial genomes may occur, independent of SNP differences.

We biopsied and analysed expanded blastocysts with a comparative genome hybridization array. Aneuploidy rates were similar between spindle transfer and intact controls (Extended Data Fig. 6a). G-banding karyotype analysis in spindle transfer and control ES cells also did not reveal any significant differences (Extended Data Fig. 6b). Finally, we examined copy number variations (CNVs) in selected spindle transfer ES cell lines for subchromosomal abnormalities. De novo CNVs were with different mtDNA mutations showed similar development patterns. Numbers inside bars, number of oocytes or embryos. MII, mature metaphase II. c, Neural progenitor cells (NPCs) derived from spindle transfer ES cells with 6 and 49 SNP differences in donor mtDNA had similar oxygen consumption rates (OCR) to non-manipulated controls. However, NPCs with 33 SNPs showed significantly reduced oxygen consumption rates compared to controls with either donor or maternal mtDNA $(P<0.05$, oneway ANOVA). See Extended Data Fig. 4a. Seahorse assay results were based on 16 technical replicates. SNPs, single nucleotide polymorphisms. Source data files are available for $\mathbf{a}, \mathbf{b}$.

detected in both spindle transfer and intact controls but were deemed of uncertain clinical significance ${ }^{18}$ (Extended Data Table 1). In summary, a total of six spindle transfer blastocysts were produced from four ovarian stimulation cycles in carriers (Extended Data Table 2). These outcomes were comparable to controls.

A small amount of maternal mtDNA carry-over is common during spindle transfer, resulting in low heteroplasmy in human embryos and in non-human primate offspring (typically below $2 \%)^{19,20}$. Here, all examined spindle transfer zygotes and cleaving embryos $(n=22)$ contained more than $99 \%$ donor mtDNA (Table 1). Similar outcomes were observed in 13 out of 15 ES cell lines (87\%) established from control spindle transfer blastocysts, regardless of donor mtDNA (Supplementary Table 3). However, two sibling ES cell lines (ST-ES7 and ST-ES8), generated by a combination of maternal U5a and donor H1b mtDNA (33 SNPs), displayed high levels of maternal mtDNA ( $81 \%$ and $94 \%$, respectively) (Table 1). Extended passaging resulted in a complete loss of donor mtDNA and a return to the original maternal mtDNA haplotype. By contrast, another sibling ES cell line generated from maternal U5a, but with donor V3 (ST-ES9; 33 SNPs) maintained donor mtDNA.

Among the carrier spindle transfer ES cell lines, 3243ST-ES1 also demonstrated 20\% maternal H49 mtDNA (Table 1). However, this maternal haplotype did not include the A3243G mutation (Supplementary Table 3). Maternal mtDNA levels in this cell line gradually increased during extended culture to $90 \%$ at passage 8 and homoplasmy at passage 10 (Fig. 3c). However, another sibling 3243STES2 generated by the same maternal and donor mtDNA combinations did not show a reversal (Table 1 and Supplementary Table 3 ).

We expanded our study to include eight ES cell lines derived by somatic cell nuclear transfer (SCNT, NT-ES cells) that also carry donor oocyte mtDNA ${ }^{21-23}$ (Table 1 and Supplementary Table 4). We identified that NT-ES8 displayed a gradual increase in maternal (somatic) mtDNA from $19 \%$ at passage 2 to $100 \%$ at passage 10 (Table 1 and Extended Data Fig. 7a). We also investigated whether the reversal is specific to undifferentiated ES cells or could occur during differentiation. Several reversed and non-reversed ES cells were differentiated in vitro into NPCs and cardiomyocytes, and in vivo into teratomas (Extended Data Fig. 5). Maternal mtDNA levels were measured before and after differentiation. 
LETTER RESEARCH

Table 1 | Donor mtDNA in pre-implantation MRT embryos and ES cell lines

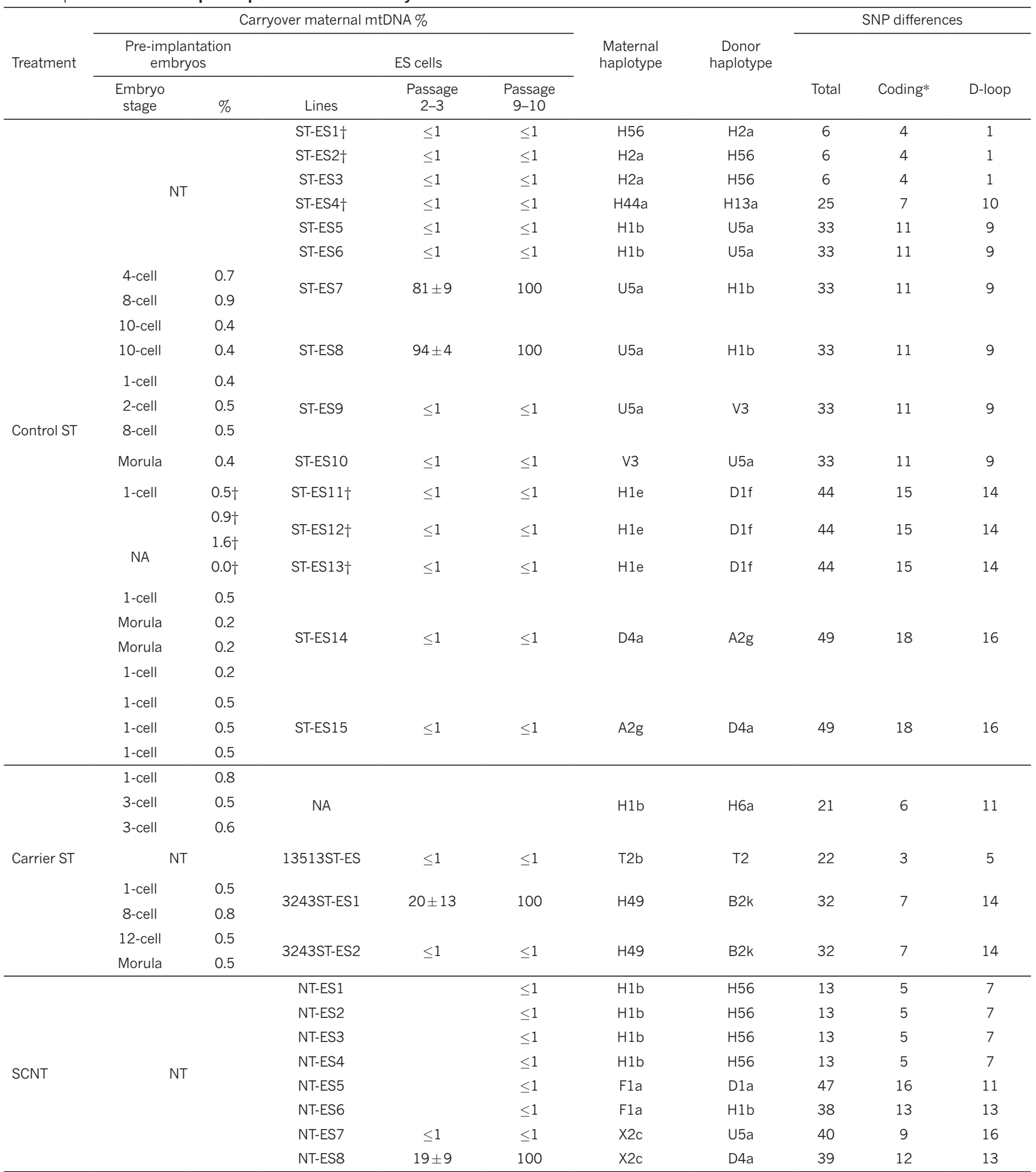

*SNPs resulting in amino acid change in protein-coding genes and residing in RNA genes. NT, not tested. NA, not applicable. ST, spindle transfer; SCNT, somatic cell nuclear transfer.

†Ref. 19.

We observed that maternal mtDNA levels in the reversed 3243ST-ES1 reduced to undetectable levels in some tissues but were slightly elevated in other cell types compared to the initial $4 \%$ in undifferentiated ES cells (Fig. 3a). The maternal mtDNA was undetectable during in vivo and in vitro differentiation of the non-reversed sibling cell line 3243ST-ES2 (Supplementary Table 3). By contrast, maternal mtDNA levels increased in all tested differentiated tissues in the reversed ST-ES7 and NT-ES8 (Fig. 3a and Supplementary Tables 3, 4). These results demonstrate that the mtDNA reversion phenomenon is not unique to ES cells and occurs during differentiation, raising the possibility that reversal to the mutant mtDNA may occur in some MRT children.

Based on our observations that specific haplotype combinations led to a reversal of the maternal mtDNA, two mechanisms were 
a

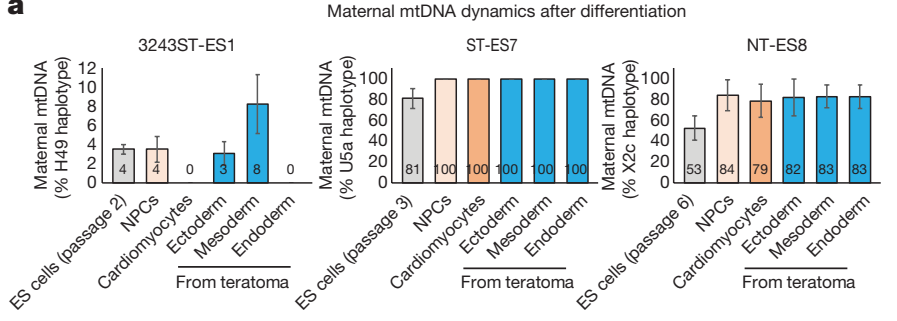

b

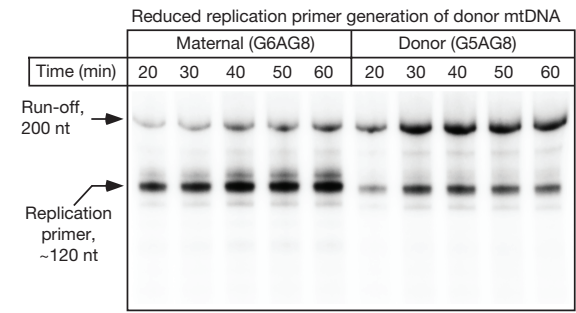

e

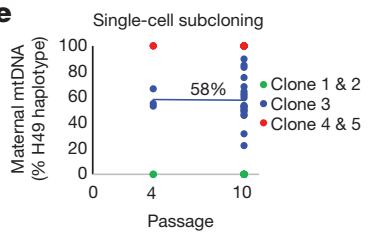

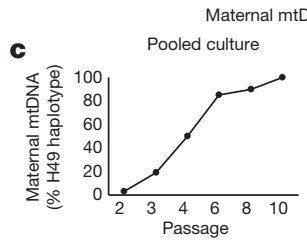

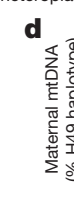

\section{f}

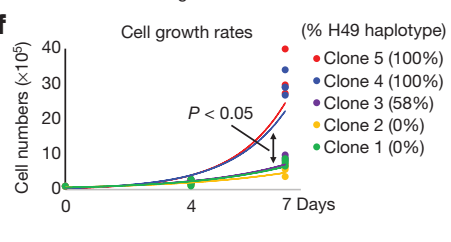

Figure 3 Mechanisms affecting mtDNA reversal. a, Maternal mtDNA heteroplasmy changes in reversed 3243ST-ES1, ST-ES7 and NT-ES8 during in vitro and in vivo differentiation $(n=1)$. Bars represent a mean heteroplasmy of maternal mtDNA based on all SNP positions. Data are shown as mean \pm s.d. See also 3243ST-ES1, ST-ES7 and NT-ES8 in Supplementary Tables 3 and 4 . b. Polymorphism in the CSBII region results in decreased efficiency of replication primer generation by mitochondrial RNA polymerase. The 311-315CCCCC polymorphism is a shortening of the first $\mathrm{G}$ stretch in the $\mathrm{G}$ quadruplex region of mtDNA (G5 versus G6), responsible for transcription termination and replication primer generation. c, Heteroplasmy rates for the maternal mtDNA (H49 haplotype) gradually increased during extended in vitro culture of 3243STES1 and reached homoplasmy $(n=1)$. See also Supplementary Table 3. d. The heteroplasmy levels also increased during ES cell colony subculture $(n=1)$. See also Supplementary Table 3. e, Maintenance of stable heteroplasmy in progeny of individually cultured cells. Heteroplasmy levels for maternal mtDNA were measured by amplification refractory mutation system-qPCR ( $n=3$ technical replicates) and whole mtDNA sequencing $(n=1)$. Data points at passage 10 are maternal mtDNA at individual SNPs. See also Supplementary Table 3. f, Faster cell growth and proliferation rates in clones containing higher maternal mtDNA heteroplasmy. $P<0.05$; one-way ANOVA; $n=4$ technical replicates. Source data files are available for $\mathbf{e}$ and $\mathbf{f}$.

investigated: preferential replication of specific haplotypes and the capability of certain mtDNA endow cells with growth advantages ${ }^{24,25}$. We first focused on the highly polymorphic $\mathrm{D}$-loop region, called conserved sequence box II (CSBII) ${ }^{25}$. It has been shown that a polymorphism in CSBII (G5AG7) affects efficiency of mitochondrial transcription termination and replication primer generation ${ }^{25}$. When we analysed the donor and maternal mtDNA in a total of 26 ES cell lines comprised of 18 different haplotype combinations, we noted that two reversed sibling lines, ST-ES7 and ST-ES8 carried donor mtDNA with a G5AG8 polymorphism while the maternal haplotype was G6AG8 (Supplementary Table 5). Using in vitro transcription assays, we analysed whether synthesis of the replication primer by mitochondrial RNA polymerase was affected and found that the deletion of a single guanosine residue (G5AG8 versus G6AG8) in donor mtDNA resulted in a fourfold reduction of replication primer synthesis (Fig. 3b). These results suggest that certain mtDNA haplotypes varying in the CSBII sequence provide more efficient synthesis of the replication primer that may, subsequently, confer replicative advantage. Sequence analysis did not find CSBII SNP differences in the remaining two reversed lines, 3243ST-ES1 and NT-ES8. However, a number of other D-loop polymorphisms were observed in the coreTAS region, which is also implicated in the regulation of mtDNA replication ${ }^{26}$. Whereas the exact mechanisms by which these polymorphisms affect replication remain unclear, we speculate that, similar to the CSBII, they may contribute to replication bias of a particular mtDNA haplotype.

Because other replication-independent mechanisms may affect reversal, we also examined 3243ST-ES1 and NT-ES8 in whole cultures versus individual cell clones. Starting maternal mtDNA levels increased with passaging in whole cultures (Fig. 3c, d, Extended Data Fig. 7a and Supplementary Tables 3, 4). However, when we dissociated ES cells into individual cells and cultured isolated single-cell clones, the starting mtDNA levels varied in different clones but heteroplasmy did not change with passaging ${ }^{23}$ (Fig. 3e and Supplementary Table 3). Notably, we observed substantial differences in cell proliferation and growth rates among different clones. Those with higher maternal mtDNA levels exhibited significantly faster growth rates $(P<0.05)$ than those with lower maternal mtDNA (Fig. 3f). These results suggest that certain mtDNA haplotypes confer ES cells with faster growth and proliferative advantages. Thus, in mixed cultures consisting of cells with varying degrees of heteroplasmy, a sub-population of cells with higher maternal mtDNA may overgrow cells with donor mtDNA. This possibility is independent of detectable mitochondrial activity, as complex I and complex IV enzyme activities were similar (Extended Data Fig. 7b).

In summary, among factors that might contribute to mtDNA reversion, several appear to be unlikely, including the MRT method (spindle transfer, pronuclear transfer or somatic cell nuclear transfer $)^{27,28}$, the presence of pathogenic mtDNA mutations and the genetic distance between donor and maternal mtDNA measured in total SNPs ${ }^{28}$. A possible mechanism could be bias towards preferential amplification of mtDNA haplotypes with specific D-loop polymorphisms. Therefore, we propose selecting compatible donors harbouring CSBII or other D-loop sequences similar to the maternal mtDNA. While the number of tested combinations in our study was small, a proposed order of replication advantage in mtDNA is: $\mathrm{H} 56>\mathrm{H} 1 \mathrm{~b}, \mathrm{U} 5 \mathrm{a}>\mathrm{H} 1 \mathrm{~b}>$ F1a, U5a $>$ X2c $>$ D4a and H49 $>$ B2k. However, stochastic or bottleneck mtDNA amplification during early embryo development may also coexist ${ }^{29,30}$.

We show that some mtDNA haplotypes could affect cell growth and proliferation thereby providing selective advantage for cells with maternal mtDNA. Future applications of MRT will require additional studies evaluating compatible donor mtDNA haplotypes to avoid reversion to mutant mtDNA.

Online Content Methods, along with any additional Extended Data display items and Source Data, are available in the online version of the paper; references unique to these sections appear only in the online paper.

Received 14 March; accepted 2 November 2016.

Published online 30 November 2016.

1. Archer, S. L. Mitochondrial dynamics-mitochondrial fission and fusion in human diseases. N. Engl. J. Med. 369, 2236-2251 (2013).

2. Koopman, W. J., Willems, P. H. \& Smeitink, J. A. Monogenic mitochondrial disorders. N. Engl. J. Med. 366, 1132-1141 (2012).

3. Schon, E. A., DiMauro, S. \& Hirano, M. Human mitochondrial DNA: roles of inherited and somatic mutations. Nat. Rev. Genet. 13, 878-890 (2012).

4. Wallace, D. C. \& Chalkia, D. Mitochondrial DNA genetics and the heteroplasmy conundrum in evolution and disease. Cold Spring Harb. Perspect. Biol. 5, a021220 (2013).

5. Gorman, G. S. et al. Mitochondrial donation-how many women could benefit? N. Engl. J. Med. 372, 885-887 (2015). 
6. Wolf, D. P., Mitalipov, N. \& Mitalipov, S. Mitochondrial replacement therapy in reproductive medicine. Trends Mol. Med. 21, 68-76 (2015).

7. Craven, L. et al. Pronuclear transfer in human embryos to prevent transmission of mitochondrial DNA disease. Nature 465, 82-85 (2010).

8. Tachibana, M. et al. Mitochondrial gene replacement in primate offspring and embryonic stem cells. Nature 461, 367-372 (2009).

9. Wallace, D. C. A mitochondrial bioenergetic etiology of disease. J. Clin. Invest. 123, 1405-1412 (2013).

10. McClelland, K. MELAS Within a family: Mitocondrial DNA Heteroplamy and Clinical Varability. MSc thesis, California State University (2014).

11. Monnot, S. et al. Segregation of mtDNA throughout human embryofetal development: m.3243A $>\mathrm{G}$ as a model system. Hum. Mutat. 32, 116-125 (2011).

12. Smeets, H. J., Sallevelt, S. C., Dreesen, J. C., de Die-Smulders, C. E. \& de Coo, I. F. Preventing the transmission of mitochondrial DNA disorders using prenatal or preimplantation genetic diagnosis. Ann. NY Acad. Sci. 1350, 29-36 (2015).

13. Kelsey, T. W., Wright, P., Nelson, S. M., Anderson, R. A. \& Wallace, W. H. A validated model of serum anti-Müllerian hormone from conception to menopause. PLoS One 6, e22024 (2011).

14. Kelsey, T. W., Anderson, R. A., Wright, P., Nelson, S. M. \& Wallace, W. H. Data-driven assessment of the human ovarian reserve. Mol. Hum. Reprod. 18, 79-87 (2012).

15. Brown, D. T., Samuels, D. C., Michael, E. M., Turnbull, D. M. \& Chinnery, P. F. Random genetic drift determines the level of mutant mtDNA in human primary oocytes. Am. J. Hum. Genet. 68, 533-536 (2001).

16. Boucret, L. et al. Relationship between diminished ovarian reserve and mitochondrial biogenesis in cumulus cells. Hum. Reprod. 30, 1653-1664 (2015).

17. Woodson, J. D. \& Chory, J. Coordination of gene expression between organellar and nuclear genomes. Nat. Rev. Genet. 9, 383-395 (2008).

18. Kearney, H. M., Thorland, E. C., Brown, K. K., Quintero-Rivera, F. \& South, S. T. American College of Medical Genetics standards and guidelines for interpretation and reporting of postnatal constitutional copy number variants. Genet. Med. 13, 680-685 (2011).

19. Tachibana, M. et al. Towards germline gene therapy of inherited mitochondrial diseases. Nature 493, 627-631 (2013).

20. Paull, D. et al. Nuclear genome transfer in human oocytes eliminates mitochondrial DNA variants. Nature 493, 632-637 (2013).

21. Tachibana, M. et al. Human embryonic stem cells derived by somatic cell nuclear transfer. Cell 153, 1228-1238 (2013).

22. Ma, H. et al. Metabolic rescue in pluripotent cells from patients with mtDNA disease. Nature 524, 234-238 (2015)

23. Kang, E. et al. Age-related accumulation of somatic mitochondrial DNA mutations in adult-derived human iPSCs. Cell Stem Cell 18, 625-636 (2016).

24. Burgstaller, J. P., Johnston, I. G. \& Poulton, J. Mitochondrial DNA disease and developmental implications for reproductive strategies. Mol. Hum. Reprod. 21, 11-22 (2015).

25. Agaronyan, K., Morozov, Y. I., Anikin, M. \& Temiakov, D. Mitochondrial biology. Replication-transcription switch in human mitochondria. Science $\mathbf{3 4 7}$ 548-551 (2015).

26. Jemt, E. et al. Regulation of DNA replication at the end of the mitochondrial D-loop involves the helicase TWINKLE and a conserved sequence element Nucleic Acids Res. 43, 9262-9275 (2015)
27. Yamada, M. et al. Genetic drift can compromise mitochondrial replacement by nuclear transfer in human oocytes. Cell Stem Cell 18, 749-754 (2016).

28. Hyslop, L. A. et al. Towards clinical application of pronuclear transfer to prevent mitochondrial DNA disease. Nature 534, 383-386 (2016).

29. Lee, H. S. et al. Rapid mitochondrial DNA segregation in primate preimplantation embryos precedes somatic and germline bottleneck. Cell Reports 1, 506-515 (2012).

30. Koehler, C. M. et al. Replacement of bovine mitochondrial DNA by a sequence variant within one generation. Genetics 129, 247-255 (1991).

Supplementary Information is available in the online version of the paper.

Acknowledgements The authors acknowledge the OHSU Embryonic Stem Cell Research Oversight Committee and the Institutional Review Board for oversight and guidance. We thank all study participants for tissue donations and the Women's Health Research Unit staff, University Fertility Consultants and the Reproductive Endocrinology and Infertility Division in the Department of Obstetrics and Gynecology, Oregon Health and Science University for support and procurement of human gametes. Studies were supported by the Leducq Foundation, OHSU institutional funds and Cincinnati Children's Hospital Research Foundation. Work in the laboratory of J.C.I.B. was supported by the G. Harold and Leila Y. Mathers Charitable Foundation, the Leona M. and Harry B. Helmsley Charitable Trust and the Moxie Foundation. A.P.L. was partially supported by a fellowship from the Hewitt Foundation. P.M.R. was partially supported by a fellowship from Fundación Alfonso Martín Escudero.

Author Contributions E.K., N.M.G., P.A. and S.M. conceived the study and designed the experiments. T.Hu., P.A. and A.K. evaluated clinical genetic results and coordinated recruitment of study participants. P.A. and J.J. performed skin biopsies and blood collections. P.A., D.B., D.L. and D.W. performed ovarian stimulations and oocyte retrievals. N.M.G., R.T.H. and S.M. conducted spindle transfer, intracytoplasmic sperm injection, embryo culture and establishment of ES cell lines. E.K., R.T.H., H.M., Y.Le., Y.Li, R.A., T.Ha. and N.M.G. cultured ES cells. E.K., C.V.D., Y.Le. and T.Ha. performed teratoma studies. E.K., C.V.D., Y.Li and D.J. performed mitochondrial complex assays. J.W., P.M.R. and A.P.L. performed in vitro differentiation and Seahorse assays. K.A. and D.T. performed mtDNA transcription experiments. E.K., C.V.D., R.T.H. and A.K. prepared mtDNA and performed MiSeq assays. E.K. and Y.Le. performed NGS data analysis and interpretation. E.K., C.V.D. validated mtDNA mutations by Sanger sequencing. H.M. and R.T.H. performed ARMS-qPCR. X.W., S.L. and T.Hu. performed CNV data analysis. R.K. and C.C. performed the comparative genome hybridization array. S.O. performed G-banding karyotypes. E.K., J.W., D.P.W., J.C.I.B., P.A. and S.M. analysed data and wrote the paper.

Author Information Reprints and permissions information is available at www.nature.com/reprints. The authors declare no competing financial interests. Readers are welcome to comment on the online version of the paper. Correspondence and requests for materials should be addressed to S.M. (mitalipo@ohsu.edu) and P.A. (amatop@ohsu.edu).

Reviewer Information Nature thanks E. Shoubridge and the other anonymous reviewer(s) for their contribution to the peer review of this work. 


\section{METHODS}

Study oversight. Initial study protocol approval was granted in 2011 by the Oregon Health \& Science University (OHSU) Institutional Review Board (IRB) and strictly followed the guidelines set forth by the Oregon Stem Cell Research Oversight Committee (OSCRO). OSCRO guidelines permit recruitment of research gamete donors and subsequent fertilization and generation of pre-implantation embryos for research purposes. The protocol allows testing various MRT approaches prior to and after fertilization and pre-implantation. MRT embryo development can be terminated or used for ES cell derivation as a critical step in testing the safety and efficacy of novel cell and gene therapy treatments before clinical applications. The study protocol has undergone annual continuing reviews and extensions by IRB which includes biannual monitoring of study-related procedures involving human gametes, embryos and ES cells. No federal funds were used for this study in accordance with federal policies.

Participants. Healthy oocyte and sperm donors were recruited locally, via printand web-based advertising, through OHSU Women's Health Research Unit. Oocyte donors were required to meet strict research inclusion criteria to minimize participant risk. Prior to consenting, eligible participants attended an information session, describing study goals and related clinical procedures. Carriers of mtDNA mutations were identified nationwide through print- and web-based advertising (UMDF and OHSU websites). Five families with existing children diagnosed with mitochondrial disease through MitoClinic in Cincinnati Children's Hospital Medical Center and OHSU Doernbecher Children's Hospital were identified and recruited. All families were out of state and travelled with children to OHSU for all study-related screening and procedures. Carrier oocyte donors underwent additional screening for study inclusion; strict inclusion criteria were met to minimize participant risk. Additionally, children from carrier donors provided samples for confirmation of pathogenic transmission of mtDNA mutations.

Informed consent. Written informed consent was obtained from gamete donors before any study-related procedures after a full review of study goals and clinical procedures. Consent forms for all gamete donors state that oocytes will be fertilized with sperm to generate pre-implantation embryos strictly for research purposes to develop and test novel MRT approaches. Consent forms also state that donated gametes and embryos eventually will be used for in vitro analyses or generation of ES cells but not for reproductive purposes. Written informed consent was obtained from parent before skin and blood donations from their underage children. As part of the consenting process, all participants provided written acknowledgement of the potential for incidental findings. If the participant requested to be informed, they were provided with some research findings by a physician collaborator and appropriate referrals were made. Patients undergoing standard IVF treatments were also contacted to donate immature oocytes that are routinely discarded as part of the IVF process. These participants were contacted before their scheduled oocyte retrievals. Written informed consent was obtained before egg retrieval.

Compensation. Research gamete donors were compensated for their time, effort, discomfort and inconvenience associated with the donation process at rates similar to gamete donors for reproductive purposes. Travel and lodging reimbursements were provided for mtDNA families travelling from out of state.

Controlled ovarian stimulation. Baseline screening was conducted including a medical history and physical exam, assessment of body mass index, anti-Müllerian hormone level and antral follicle count (AFC). Subjects underwent ovarian stimulation and oocyte retrieval employing standard IVF protocols and procedures ${ }^{19}$. All study-related procedures for oocyte donation took place at OHSU.

Spindle transfer. Spindle transfer was performed as previously described ${ }^{19}$. Briefly, meiotic metaphase II (MII) spindles were visualized under polarized microscopy and isolated with minimal cytoplasm (karyoplast, maternal mtDNA). The karyoplast was then placed in the perivitelline space of an enucleated oocyte (cytoplast, donor mtDNA) and fused using HVJ-E (haemagglutinating virus of Japan-envelope).

Oocyte vitrification. Oocyte vitrification was performed as previously described using commercially available human oocyte vitrification and thawing kits (Vitrification kit and Vitrification warming kit, Life Global).

Derivation of ES cells and culture. Spindle transfer blastocysts were freed from their zonae pellucidae and plated on mouse embryonic fibroblast (MEF) feeder layers on 4-well culture dishes for 5-7 days at $37^{\circ} \mathrm{C}, 3 \% \mathrm{CO}_{2}, 5 \% \mathrm{O}_{2}$ and $92 \% \mathrm{~N}_{2}$ in medium (DMEM/F12 with 10\% fetal bovine serum (FBS), 10\% knockout serum replacement (KSR), $0.1 \mathrm{mM}$ non-essential amino acids, $1 \mathrm{mM}$ L-glutamine, $0.1 \mathrm{mM}$ $\beta$-mercaptoethanol, $5 \mathrm{ng} \mathrm{ml}^{-1}$ basic fibroblast growth factor (bFGF), $10 \mu \mathrm{M}$ ROCK inhibitor) as previously described ${ }^{19}$. Attached blastocyst outgrowths were manually minced into small pieces, re-plated onto fresh plates and maintained in knockout DMEM medium (Invitrogen) supplemented with $20 \% \mathrm{KSR}, 0.1 \mathrm{mM}$ non-essential amino acids, $1 \mathrm{mM}$ L-glutamine, $0.1 \mathrm{mM} \beta$-mercaptoethanol, penicillin-streptomycin and $4 \mathrm{ng} \mathrm{ml}^{-1} \mathrm{bFGF}$ for further propagation and analysis. All cell lines were negative for mycoplasma contamination.
mtDNA transcription assays. In vitro transcription anti-termination assays were performed as described previously ${ }^{25}$ using PCR-amplified templates containing region 202-481 of donor (H1b) or maternal (U5a) mtDNA. The products of the transcription reactions were resolved by $20 \%$ PAGE containing $6 \mathrm{M}$ urea and visualized by PhosphoImager (GE Health).

Cell growth and proliferation assays. ES cells were adapted to grow under feederfree conditions on Matrigel matrix in mTeSR1 medium (STEMCELL technologies) ${ }^{31}$ The cells were dissociated with Accutase (Life Technologies) for $2 \mathrm{~min}$ and approximately $10^{5}$ cells were seeded into each $60-\mathrm{mm}$ dish. The cells were periodically harvested and counted using a Countess Automated Cell Counter (Invitrogen).

NPC differentiation and culture. A previously published protocol with minor modifications was used for NPC differentiation ${ }^{22}$. In brief, ES cells were maintained on MEFs in CDF12 medium before NPC differentiation. CDF12 medium contained DMEM/F12 (Life Technology), 20\% KSR (Life Technologies), $2 \mathrm{mM}$ Glutamax (Life Technologies), $0.1 \mathrm{mM}$ non-essential amino acids (Life Technology), $0.1 \mathrm{mM} \beta$-mercaptoethanol (Life Technologies) and $4 \mathrm{ng} \mathrm{ml}^{-1}$ FGF2 (Peprotech). ES cells were disaggregated with Collagenase IV (Life Technologies) and allowed to grow to about $40 \%$ confluence. To initiate neural induction, cells were washed twice with $1 \times$ DPBS without calcium and magnesium (Corning Cellgro) and the medium was then changed to Neural Induction Medium 1 (NIM-1: 50\% Advanced DMEM/F12 (Invitrogen), 50\% Neurobasal (Invitrogen), $1 \times$ B27 (Invitrogen), $1 \times \mathrm{N} 2$ (Invitrogen), $2 \mathrm{mM}$ Glutamax and $10 \mathrm{ng} \mathrm{ml}^{-1} \mathrm{hLIF}$ (Peprotech), $4 \mu$ M CHIR99021 (Selleckchem), $3 \mu$ M SB431542 (Selleckchem), $2 \mu \mathrm{M}$ dorsomorphin (Sigma) and $0.1 \mu \mathrm{M}$ Compound E (EMD Chemicals Inc.). After 2 days in culture in NIM-1 medium, cells were switched to Neural Induction Medium 2 (NIM-2: 50\% Advanced DMEM/F12, 50\% Neurobasal, $1 \times$ N2, $1 \times$ B27, $2 \mathrm{mM}$ GlutaMAX and $10 \mathrm{ng} \mathrm{ml}^{-1} \mathrm{hLIF}, 4 \mu \mathrm{M}$ CHIR99021, $3 \mu \mathrm{M}$ SB431542 and $0.1 \mu \mathrm{M}$ Compound E). Cells were further cultured in NIM-2 for 5 days with daily medium change. On the last day in NIM-2 medium, cells were treated overnight with $10 \mu$ M Y27632 (Selleckchem) and 20-30 'dome'-shaped colonies were manually picked and digested with Accumax (Innovative Cell Technologies) for $10 \mathrm{~min}$ at $37^{\circ} \mathrm{C}$. After Accumax treatment cells were gently disaggregated into single cells and re-plated onto Matrigel-coated 6-well plates at a density of about $3.5 \times 10^{4} \mathrm{per} \mathrm{cm}^{2}$ in Neural Progenitor cell Maintenance Medium (NPMM: 50\% Advanced DMEM/ F12, 50\% Neurobasal, $1 \times$ B27, $1 \times$ N2, 2 mM GlutaMAX, 10 ng ml $^{-1}$ hLIF, $3 \mu \mathrm{M}$ CHIR99021 and $2 \mu \mathrm{M}$ SB431542) supplemented with $10 \mu \mathrm{M}$ Y27632. NPCs were maintained on Matrigel-coated dishes in NPMM. NPCs were passaged when they reached around $70 \%$ to $80 \%$ confluence using Accumax and replated at a density of $3 \times 10^{4}$ per $\mathrm{cm}^{2}$ with daily medium change. For the initial six passages, NPCs were pre-treated with $10 \mu \mathrm{M}$ Y27632 overnight before and during cell splitting. The study was randomized, and the investigators were blinded to treatment allocations in collaborators' laboratories.

Cardiomyocyte differentiation. Cardiomyocyte differentiation was performed based on a GiWi (GSK3 inhibitor and Wnt inhibitor) protocol described previously ${ }^{32}$. Briefly, ES cells were grown on Matrigel-coated plates in mTeSR 1 medium to $80-90 \%$ confluence before passaging with Accutase and then re-seeded at $0.5-1.5$ million cells per well in 12 -well plates in $1 \mathrm{ml}$ of $\mathrm{mTeSR} 1$ plus $10 \mu \mathrm{M}$ Y27632. On day 5, cells were incubated with 6-12 $\mu$ M CHIR99021 (Selleckchem) for 16-24h after which the medium was replaced with $2 \mathrm{ml}$ of RPMI/B27 (withou insulin) and cultured for two days. On day $8,2 \mathrm{ml}$ combined medium was prepared by mixing $1 \mathrm{ml}$ of medium collected from the 12 -well plate with $1 \mathrm{ml}$ fresh RPMI/ B27 (without insulin) medium. Medium on the cells was then replaced with $2 \mathrm{ml}$ combined medium with $5 \mu \mathrm{M}$ IWP2 (Tocris) and cells were cultured for $48 \mathrm{~h}$. At day 10, $2 \mathrm{ml}$ of fresh RPMI/B27 (without insulin) was added to each well of the 12-well plate. Starting from day 12, medium was changed every three days with $2 \mathrm{ml}$ per well of RMPI/B27 (with insulin). Contracting cardiomyocytes were observed as early as day 17 from the initial passaging of ES cells.

Differentiated cell types were characterized by immunocytochemistry as described previously ${ }^{22}$.

Teratoma assay. ES cells were injected into the femoral region of 6-week-old, male SCID mice (Charles River). Mice with tumours were euthanized and teratomas were isolated, sectioned and histologically characterized for the presence of representative tissues as described previously ${ }^{22}$

Assessment of mitochondrial function. Mitochondrial respiratory chain enzymatic activities (complex I and IV) were measured by spectrophotometry, as previously described ${ }^{23,33}$. In brief, intact mitochondria were isolated from fibroblasts and treated with and without $3 \mathrm{mM}$ rotenone at $340 \mathrm{~nm}$ wavelength for $5 \mathrm{~min}$. Differences of absorbance per minute were obtained, and the specificity of COMI activity was estimated by the percentage of rotenone inhibition.

For live cell oxygen consumption, a XF96 Extracellular Flux Analyzer (Seahorse Biosciences) was used to measure oxygen consumption rates (OCR) and extracellular acidification rates as described previously ${ }^{22}$. In brief, NPCs were seeded at a density of 30,000 cells per well of a XF96 cell-culture microplate and incubated 
for $24 \mathrm{~h}$ to allow cells to attach. Prior to the assay, NPCs were equilibrated for $1 \mathrm{~h}$ in unbuffered XF-assay medium supplemented with $25 \mathrm{mM}$ glucose, $1 \mathrm{mM}$ sodium pyruvate, $2 \mathrm{mM}$ glutamax, $1 \times$ non-essential amino acids and $1 \%(\mathrm{v} / \mathrm{v})$ FBS in a non- $\mathrm{CO}_{2}$ incubator. Sequential compound injections of oligomycin $\left(0.5 \mu \mathrm{g} \mathrm{ml}^{-1}\right)$, carbonyl cyanide 4 -(trifluoromethoxy) phenylhydrazone (FCCP, $\left.1 \mu \mathrm{M}\right)$, rotenone $(0.5 \mu \mathrm{M})$ and antimycin $\mathrm{A}(1 \mu \mathrm{M})$ were used to measure the parameters of mitochondrial respiration. Indices of mitochondrial function were calculated as basal respiration rate (baseline OCR-rotenone or antimycin A OCR), ATPdependent (basal respiration rate-oligomycin OCAR), maximal respiration rate (FCCP OCR - rotenone or antimycin A OCR) and oxidative reserve (maximal respiration rate-basal respiration rate). Each plotted value was the mean of a minimum of four replicate wells, and was normalized to total cell numbers plated. Results were presented as means \pm s.e.m. One-way ANOVA was used for three group comparisons and Student's $t$-test was used for pairwise comparisons. $P<0.05$ was considered significant. The study was randomized, and the investigators were blinded to sample allocations among different groups.

mtDNA sequencing. Mutations and general mtDNA haplotypes were determined in oocytes, blood, skin fibroblasts, urine, ES cells and differentiated tissues by whole mtDNA next generation sequencing using the Illumina MiSeq platform ${ }^{22,23}$. DNA was extracted from cells or tissues using Gentra DNA extraction kit (Qiagen), and from oocytes using Pico Pure DNA Extraction Kit (Life Technologies). mtDNA was amplified by a single PCR reaction as previously described $^{22}$. mtDNA amplification from individual oocytes was performed using 2 primer sets: 7272F 5'-GGCTCATTCATTTCTCTAACAG-3', 15712R $5^{\prime}$-TTGGCTTAGTGGGCGAAATA- $3^{\prime}$ and $15635 \mathrm{~F} 5^{\prime}$-TCCATCCTCATCC TAGCAAT-3', 7401R 5'-GGGGGCATCCATATAGTCAC-3.

Detection of mtDNA variants by Sanger sequencing. mtDNA variants present at over $10 \%$ heteroplasmy were corroborated independently by Sanger sequencing. Regions of mtDNA containing germline mutations or SNPs were amplified by PCR with previously reported primer sets using PCR Platinum SuperMix High Fidelity kit (Life Technologies) ${ }^{23}$. PCR products were purified, sequenced and analysed by Sequencher v5.0 (GeneCodes).

ARMS-qPCR and copy number measurement. The amplification refractory mutation system quantitative PCR assay (ARM-qPCR) was performed to verify heteroplasmy at mt8993T $>$ G, mt13513G $>$ A and mt3243A $>$ G as previously described ${ }^{22}$ and to measure carryover in control spindle transfer embryos and ES cells at $7843 \mathrm{~A}>\mathrm{G}, 16519 \mathrm{~T}>\mathrm{C}$ and $16278 \mathrm{~T}>\mathrm{C}^{19}$. Measurement of mtDNA copy number was performed as previously described ${ }^{34}$.

Genetic and cytogenetic analyses. Karyotyping by G-banding was performed on 20 metaphase cells from each ES cell line by the OHSU Cytogenetics Laboratory. The comparative genome hybridization array was performed by IVI Gen. CNVs were identified by SNP genotyping as previously described ${ }^{35}$ and analysed at the clinical genetic diagnosis laboratory in Cincinnati Children's Hospital Medical Center.

Statistical analysis. No statistical methods were used to predetermine sample size. The experiments were not randomized. The investigators were not blinded to allocation during experiments and outcome assessment except for neural progenitor cell and cardiomyocyte differentiations and measurements of mitochondrial oxygen consumption rates. Results are presented as means \pm s.d. or s.e.m. $P<0.05$ was considered significant. Data were analysed using Pearson non-parametric test for correlation, independent group $t$-test or $\chi^{2}$ test for pairwise comparison and ANOVA with Bonferroni analysis for multiple comparisons (IBM SPSS).

Data availability. All data generated or analysed during this study and included in this letter (and its Supplementary Information) are deposited in the NCBI SRA (SRP091883) and GEO (GSE87897).

31. Wu, J. et al. An alternative pluripotent state confers interspecies chimaeric competency. Nature 521, 316-321 (2015).

32. Lian, X. et al. Directed cardiomyocyte differentiation from human pluripotent stem cells by modulating Wnt/ $\beta$-catenin signaling under fully defined conditions. Nat. Protoc. 8, 162-175 (2013).

33. Spinazzi, M., Casarin, A., Pertegato, V., Salviati, L. \& Angelini, C. Assessment of mitochondrial respiratory chain enzymatic activities on tissues and cultured cells. Nat. Protoc. 7, 1235-1246 (2012).

34. Monnot, S. et al. Mutation dependance of the mitochondrial DNA copy number in the first stages of human embryogenesis. Hum. Mol. Genet. 22, 1867-1872 (2013).

35. $\mathrm{Ma}, \mathrm{H}$. et al. Abnormalities in human pluripotent cells due to reprogramming mechanisms. Nature 511, 177-183 (2014). 
a

Information on families with mitochondrial disease

\begin{tabular}{|c|c|c|c|c|c|c|c|}
\hline $\begin{array}{l}\text { Mitochondrial } \\
\text { disease }\end{array}$ & Family & $\begin{array}{l}\text { Affected } \\
\text { member }\end{array}$ & Age (yr) & Clinical manifestation & $\begin{array}{l}\text { Mother's } \\
\text { age (yr) }\end{array}$ & $\begin{array}{c}\text { mtDNA } \\
\text { mutation }\end{array}$ & Gene \\
\hline \multirow{4}{*}{$\begin{array}{l}\text { Leigh } \\
\text { syndrome }\end{array}$} & $\mathrm{F} 1$ & Daughter & 2 & $\begin{array}{l}\text { Seizures, metabolic acidosis, } \\
\text { developmental delay, difficulty to } \\
\text { thrive, abnormal basal ganglia and } \\
\text { enlargement heart ventricle }\end{array}$ & 22 & T8993G & $\begin{array}{c}\text { ATP6 } \\
\text { (non-syn }\end{array}$ \\
\hline & $\mathrm{F} 2$ & Son & 2.5 & $\begin{array}{l}\text { Seizures, chronic acidosis, } \\
\text { developmental delay, difficulty to thrive } \\
\text { and encephalopathy }\end{array}$ & 23 & T8993G & $\begin{array}{c}\text { ATP6 } \\
\text { (non-syn }\end{array}$ \\
\hline & F3 & Son & 12 & $\begin{array}{l}\text { Seizures, failure to thrive, difficulty in } \\
\text { breathing, enlarged heart ventricle, } \\
\text { kidney failure and optic nerve atrophy }\end{array}$ & 36 & G13513A & $\begin{array}{c}\text { ND5 } \\
\text { (non-syn }\end{array}$ \\
\hline & $\mathrm{F} 4$ & Daughter & 1 & $\begin{array}{l}\text { Seizures, difficulty to thrive, lactic } \\
\text { acidosis, neuro-motor impairment and } \\
\text { history of congenital brain abnormality }\end{array}$ & 28 & No & NA \\
\hline $\begin{array}{l}\text { MELAS } \\
\text { syndrome }\end{array}$ & F5 & $\begin{array}{l}\text { Maternal } \\
\text { sister }\end{array}$ & 23 & $\begin{array}{l}\text { Mitochondrial encephalomyopathy, } \\
\text { lactic acidosis and stroke-like } \\
\text { episodes }\end{array}$ & 32 & A3243G & $\begin{array}{c}\text { tRNA } \\
\text { (Leucine) }\end{array}$ \\
\hline
\end{tabular}

b

A3243G mutation distribution in pedigree of family 5 with MELAS syndrome

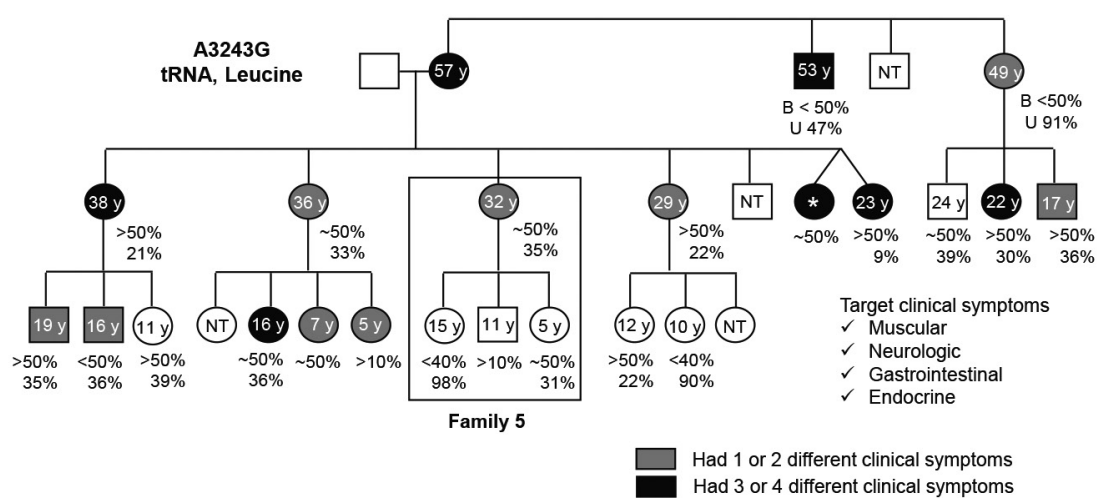

Extended Data Figure 1 | Families with mitochondrial disease. a, Families with mitochondrial disease and women of reproductive age were recruited for MRT. All Leigh syndrome families had an existing, severely affected child. F, family; non-syn, non-synonymous; NA, not applicable. b, Family 5 was selected from an extensive MELAS syndrome pedigree. Clinical phenotypes of A3243G MELAS syndrome varied even with similar heteroplasmy levels. Asterisk indicates the first MELAS patient diagnosed clinically. Heteroplasmy in blood (upper panel) and urine (lower panel). Squares, males; circles, females. B, blood; $U$, urine. NT, not tested. Percentage values refer to heteroplasmy; y, years-old. 

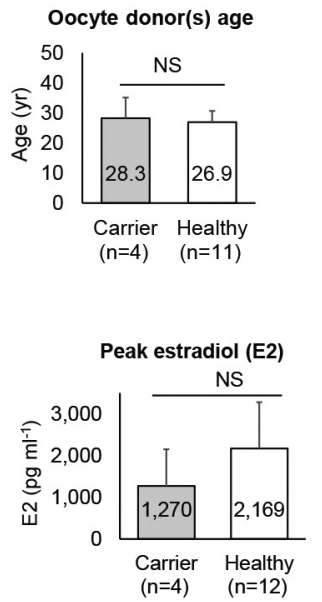

b

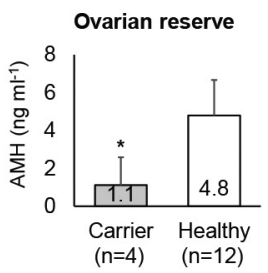

$\mathbf{f}$

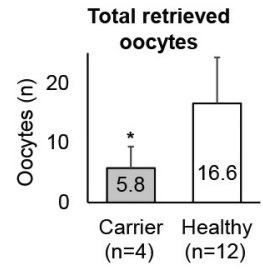

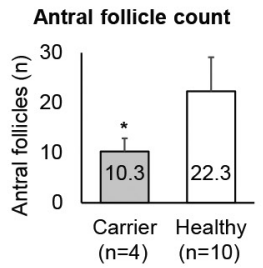

g

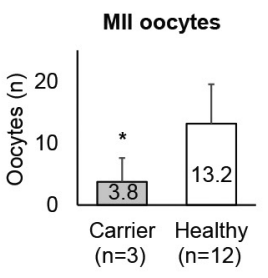

d

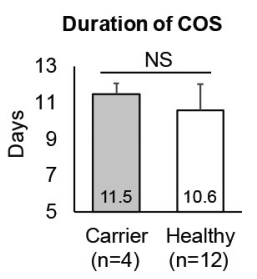

h

Responses to controlled ovarian stimulation in women carrying pathogenic mtDNA mutations

\begin{tabular}{ccccccccccc}
\hline $\begin{array}{c}\text { Oocyte } \\
\text { donor }\end{array}$ & Family & $\begin{array}{c}\text { Age } \\
(\mathrm{yr})\end{array}$ & $\begin{array}{c}\text { Duration of } \\
\text { birth control } \\
(\mathrm{yr})\end{array}$ & $\begin{array}{c}\mathrm{BMl} \\
\left(\mathrm{kg} \mathrm{m}^{-2}\right)\end{array}$ & $\begin{array}{c}\mathrm{AMH} \\
\left(\mathrm{ng} \mathrm{ml}^{-1}\right)\end{array}$ & $\begin{array}{c}\mathrm{AFC} \\
(n)\end{array}$ & $\begin{array}{c}\text { Peak E2 } \\
\left(\mathrm{pg} \mathrm{m}^{-1}\right)\end{array}$ & $\begin{array}{c}\text { Duration of } \\
\text { Stimulation } \\
(\text { days })\end{array}$ & $\begin{array}{c}\text { Retrieved } \\
\text { Oocytes }(n)\end{array}$ & $\begin{array}{c}\text { Mature } \\
\text { MII oocytes }(n)\end{array}$ \\
\hline cED1 & F1 & 22 & 2 & 22.1 & 0.2 & 9 & 280 & 11 & 3 & 2 \\
cED2 & F2 & 23 & none & 34.1 & 3.3 & 10 & 797 & 11 & 5 (premature & NA \\
cED3 & F3 & 36 & 12 & 23.5 & 0.5 & 8 & 1848 & 12 & 4 & 4 \\
cED4 & F5 & 32 & none & 33.1 & 0.4 & 14 & 2156 & 12 & 11 & 9 \\
\hline
\end{tabular}

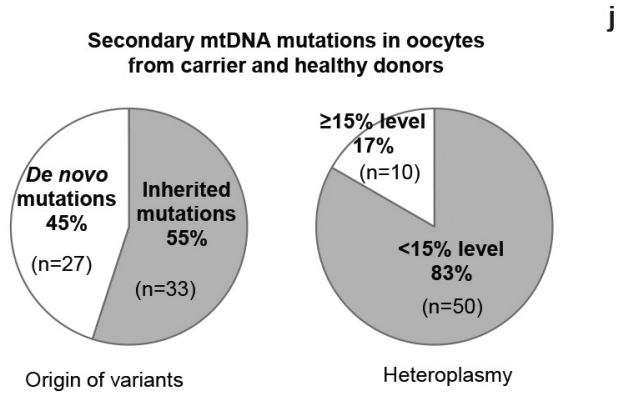

Extended Data Figure 2 | Response to controlled ovarian stimulation and oocyte characteristics. a, Age of oocyte donor(s) was similar between carrier and healthy groups. b, c, Ovarian reserve (b) and antral follicle count (c) were significantly lower in carriers than in healthy oocyte donors. d, e, Duration of controlled ovarian stimulation (d, COS) was longer in carriers and peak oestradiol (e, E2) on day of hCG trended to be lower in carriers. f, $\mathbf{g}$, Total oocyte yield (f) and number of mature oocytes (g) were significantly lower in carriers than healthy oocyte donors. $n=$ the number of controlled ovarian stimulation cycles. Data are represented as mean \pm s.d. $* P<0.05$. h, Baseline characteristics and cycle outcomes.

j
Correlation between mtDNA copy number and AMH levels

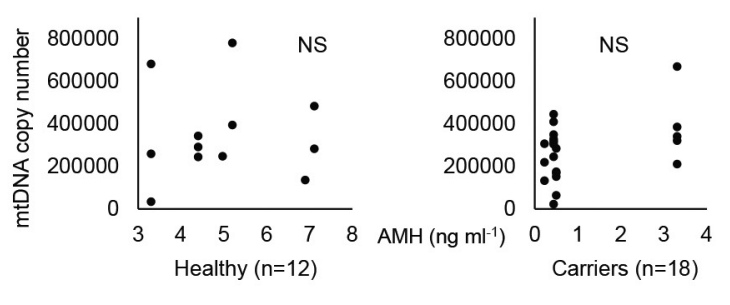

Carriers had a lower anti-Müllerian hormone (AMH) levels. Lower peak oestradiol levels were measured in cED1 and cED2. Birth control method: combined oral contraceptive, medroxyprogesterone. i, Analysis of heteroplasmic mtDNA variants detected in MII oocytes. De novo indicates unique mutations found in individual oocytes; inherited indicates mutations shared with other oocytes, sibling children or egg donors. $n=$ the number of mutations in individual oocytes. $\mathbf{j}$, anti-Müllerian hormone levels, a measure of ovarian reserve, were not correlated with mtDNA copy number. $n=$ the number of oocytes. NS, not significant. Source data files are available for $\mathbf{a}-\mathbf{g}$. 
Donor oocyte m tDNA haplotypes and SNP differences in ST embryos

\begin{tabular}{|c|c|c|c|c|c|c|c|c|c|c|c|c|}
\hline $\begin{array}{c}\text { Cyto } \\
\text { Karya }\end{array}$ & $\begin{array}{c}\text { Egg } \\
\text { donor }\end{array}$ & $\begin{array}{l}\text { hED1 } \\
(21-y r)\end{array}$ & $\begin{array}{c}\text { hED2 } \\
\text { (29-yr) }\end{array}$ & $\begin{array}{c}\text { hED3 } \\
(23-y r)\end{array}$ & $\begin{array}{l}\text { hED4 } \\
(25-y r)\end{array}$ & $\begin{array}{l}\text { hED5 } \\
(25-y r) \\
\end{array}$ & $\begin{array}{l}\text { hED6 } \\
(28-y r)\end{array}$ & $\begin{array}{l}\text { hED7 } \\
(24-y r) \\
\end{array}$ & $\begin{array}{l}\text { hED8 } \\
(34-y r)\end{array}$ & $\begin{array}{c}\text { hED9 } \\
(32-y r)\end{array}$ & $\begin{array}{l}\text { hED10 } \\
(27-y r)\end{array}$ & $\begin{array}{l}\text { hED 11 } \\
(29-y r)\end{array}$ \\
\hline $\begin{array}{c}\text { Egg } \\
\text { donor }\end{array}$ & $\begin{array}{c}\text { mtDNA } \\
\text { haplotype }\end{array}$ & L2c & D4a & $\mathrm{A} 2 \mathrm{~g}$ & B2k & U5a & V3 & T2 & $\mathrm{H} 1 \mathrm{~b}$ & $\mathrm{H} 2 \mathrm{a}$ & $\mathrm{H} 6 \mathrm{a}$ & H56 \\
\hline \begin{tabular}{|c|}
$\mathrm{hED} 1$ \\
$(21-\mathrm{yr})$ \\
\end{tabular} & $\mathrm{L} 2 \mathrm{c}$ & & & & & & & & & 57 & & \\
\hline \begin{tabular}{|c|} 
hED2 \\
$(29-y r)$ \\
\end{tabular} & D4a & & & 49 & & & & & & & & \\
\hline \begin{tabular}{|c|} 
hED3 \\
$(23-y r)$ \\
\end{tabular} & $\mathrm{A} 2 \mathrm{~g}$ & & 49 & & & & & & & & & \\
\hline \begin{tabular}{|c|} 
hED5 \\
$(25-y r)$ \\
\end{tabular} & U5a & & & & & & 33 & & 33 & & & \\
\hline \begin{tabular}{|c|} 
hED6 \\
$(28-y r)$ \\
\end{tabular} & V3 & & & & & 33 & & & & & & \\
\hline \begin{tabular}{|c|} 
hED8 \\
$(34-y r)$ \\
\end{tabular} & $\mathrm{H} 1 \mathrm{~b}$ & & & & & 33 & & & & & & \\
\hline $\begin{array}{c}\text { hED9 } \\
(32-y r) \\
\end{array}$ & $\mathrm{H} 2 \mathrm{a}$ & 57 & & & & & & & & & & 6 \\
\hline \begin{tabular}{|l|} 
hED11 \\
(29-yr) \\
\end{tabular} & H56 & & & & & & & & & 6 & & \\
\hline \begin{tabular}{|c|} 
cED1 \\
$(22-y r)$
\end{tabular} & $\mathrm{H} 1 \mathrm{~b}$ & & & & & & & & & & 21 & \\
\hline \begin{tabular}{|c|} 
cED3 \\
$(36-y r)$
\end{tabular} & $\mathrm{T} 2 \mathrm{~b}$ & & & & & & & 22 & & & & \\
\hline \begin{tabular}{|c|} 
cED4 \\
$(32-y r)$ \\
\end{tabular} & $\mathrm{H} 49$ & & & & 32 & & & & & & & \\
\hline
\end{tabular}

b

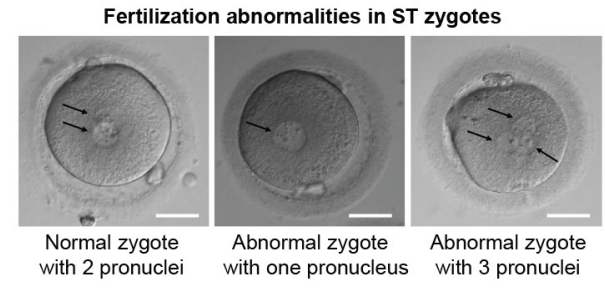

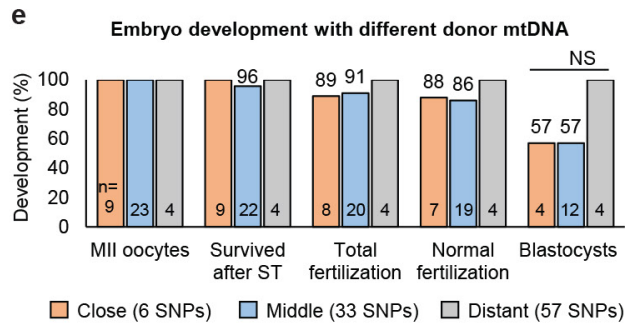

C Fertilization abnormalities in ST zygotes and embryos

\begin{tabular}{|c|c|c|c|c|c|c|c|}
\hline \multirow[b]{2}{*}{ Treatment } & \multirow{2}{*}{$\begin{array}{l}\text { Total fertilized } \\
\text { zygotes (n) }\end{array}$} & \multirow{2}{*}{$\begin{array}{c}\text { Total abnormal } \\
\text { fertilized zygotes } \\
(\%)\end{array}$} & \multicolumn{3}{|c|}{ Abnormal No. of pronuclei } & \multirow[b]{2}{*}{ Blastocysts } & \multirow[b]{2}{*}{ Karyotypes } \\
\hline & & & One & $\begin{array}{c}\text { Three } \\
(\%)\end{array}$ & $\begin{array}{c}\text { Abnormal } \\
\text { divided }\end{array}$ & & \\
\hline Intact control & 17 & $1(6)$ & 1 & 0 & 0 & 0 & \\
\hline \multirow{2}{*}{ Control ST } & \multirow{2}{*}{32} & \multirow{2}{*}{$2(6)$} & 1 & & 0 & 0 & \\
\hline & & & & $1(3)$ & & 1 & $69, X X Y$ \\
\hline Carrier ST & 12 & $4(33)$ & 1 & $2(17)$ & 1 & 0 & \\
\hline
\end{tabular}

d Fertilization and embryo development of frozen ST oocytes

\begin{tabular}{lcccccccc}
\hline Treatment & $\begin{array}{c}\text { MII oocytes } \\
(\mathrm{n})\end{array}$ & $\begin{array}{c}\text { Survived } \\
\text { after ST } \\
(\%)\end{array}$ & $\begin{array}{c}\text { Total } \\
\text { fertilization } \\
(\%)\end{array}$ & $\begin{array}{c}\text { Normal } \\
\text { fertilization } \\
(\%)\end{array}$ & $\begin{array}{c}\text { Abnormal No. } \\
\text { pronuclei }\end{array}$ & $\begin{array}{c}\text { Normal } \\
\text { Onorula } \\
\text { Onree (\%) }\end{array}$ & $\begin{array}{c}\text { Normal } \\
\text { blastocysts } \\
(\%)\end{array}$ \\
\hline $\begin{array}{l}\text { Vitrified cytoplasts/ } \\
\text { Fresh spindles }\end{array}$ & 6 & $6(100)$ & $6(100)$ & $4(67)$ & 1 & $1(17)$ & $4(100)$ & $1(25)$ \\
\hline $\begin{array}{l}\text { Vitrified spindles/ } \\
\text { Fresh cytoplasts }\end{array}$ & 6 & $6(100)$ & $3(50)$ & $2(67)$ & 0 & $1(33)$ & $2(100)$ & $1(50)$ \\
\hline
\end{tabular}

Extended Data Figure 3 | Fertilization and development after spindle transfer. a, Whole mtDNA sequencing was performed to identify haplotypes of all egg donors and spindle transfer was performed to match various haplotypes. Cyto, cytoplast; Karyo, karyoplast. b, Normal fertilization ( 2 pronuclei) and abnormal fertilization ( 1 or 3 pronuclei); see arrows. Scale bars, $50 \mu \mathrm{m}$. c, Carrier spindle transfer showed higher abnormal fertilization than controls. One zygote from the control spindle transfer group with three pronuclei developed to a blastocyst and displayed a 69, XXY karyotype. d, The blastulation rate was similar between vitrified cytoplasm with fresh spindles and vitrified spindles with fresh cytoplasm $(P>0.05$; $t$-test $)$. e, Control spindle transfer embryo development as a function of donor mtDNA matching distances. The numbers on the top of bars are percentage of embryo development. $n=$ the number of embryos; NS, not significant $(P>0.05$; $t$-test). 

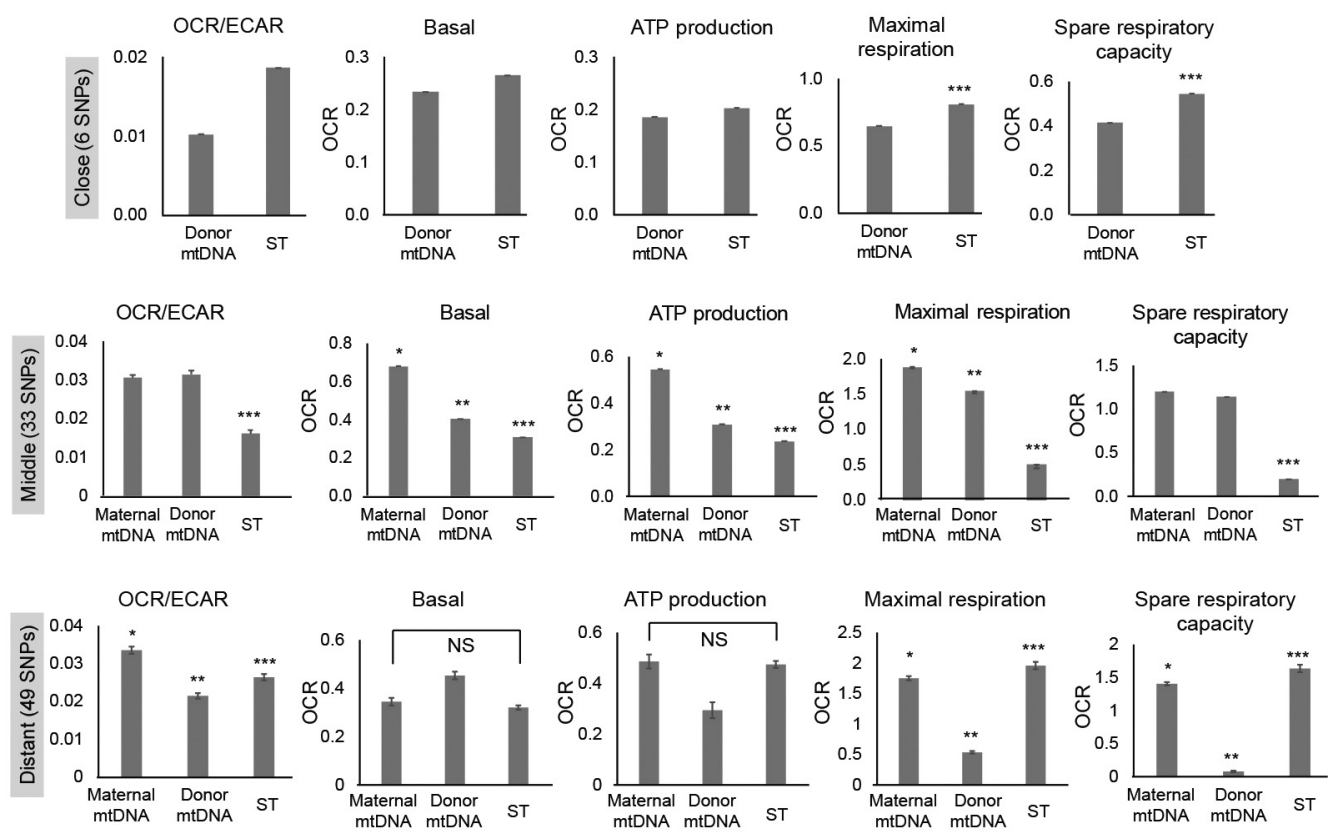

b

Mitochondrial respiratory chain enzyme activity in ST-ES cells

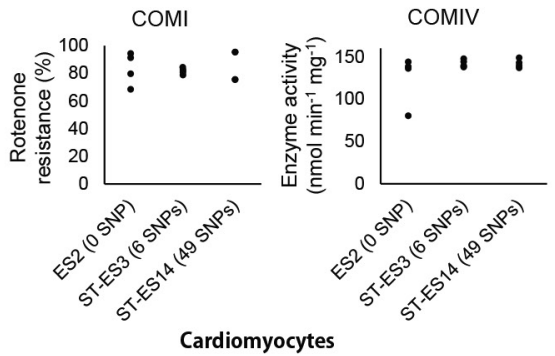
Extended Data Figure $4 \mid$ Mitochondrial function in cells with donor
mtDNA. a, Energy metabolism $\left(\frac{O C R}{\mathrm{ECAR}}\right)$ was measured and compared between neural progenitor cells (NPCs) derived from MRT and control embryos carrying either donor or maternal mtDNA. OCR, oxygen consumption rate (representing oxidative phosphorylation); ECAR, extracellular acidification rate (representing glycolysis). NPCs from MRT ES cells with 6 and 49 SNP differences displayed comparable oxygen consumption rates to NPCs harbouring maternal or donor mtDNA except maximal respiration in the $49 \mathrm{SNP}$ group. The oxygen consumption rate was reduced in NPCs with 33 SNPs. The oxygen consumption rate data

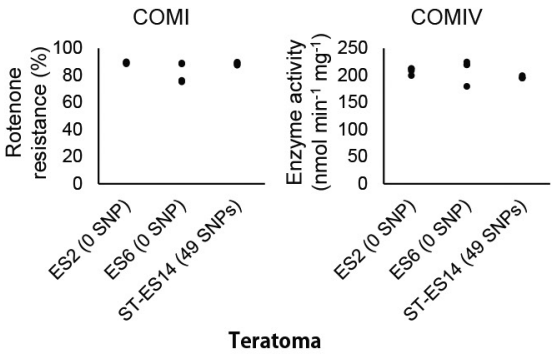

were normalized by live cell DNA content. $* P<0.05$ versus host mtDNA, $* * P<0.05$ versus donor mtDNA, $* * * P<0.05$ versus spindle transfer ( $t$-test for 6 SNPs and one-way ANOVA for 33 and 49 SNPs, $n=16$ technical replicates). Data are shown as mean \pm s.e.m. NS, not significant. b, Mitochondrial respiratory chain enzyme activity in differentiated cells from spindle transfer ES cell lines. Mitochondrial complex I and IV activities in differentiated cells from spindle transfer ES cell lines carrying donor mtDNA with 49 SNP differences were comparable to controls with either donor or maternal mtDNA $(P>0.05)$. One-way ANOVA, $n=4$ technical replicates. Source data file is available for $\mathbf{b}$. 


\section{RESEARCH LETTER}

a

In vivo and in vitro differentiation of ST-ES cells

\begin{tabular}{|c|c|c|c|c|c|c|c|}
\hline No. & Cell line & $\begin{array}{c}\text { Maternal } \\
\text { mtDNA haplotype }\end{array}$ & $\begin{array}{c}\text { Donor } \\
\text { mtDNA haplotype }\end{array}$ & $\begin{array}{c}\text { SNP } \\
\text { difference }\end{array}$ & Teratoma & NPCs & Cardiomyocytes \\
\hline 1 & ES1 & \multicolumn{2}{|c|}{ - H1b control - } & 0 & NT & yes & yes \\
\hline 2 & ES2 & \multicolumn{2}{|c|}{------ D4a control --------- } & 0 & yes & yes & yes \\
\hline 3 & ES3 & \multicolumn{2}{|c|}{ 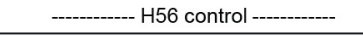 } & 0 & NT & yes & yes \\
\hline 4 & ES6 & \multicolumn{2}{|c|}{------ A2g control -------- } & 0 & yes & yes & yes \\
\hline 5 & ST-ES3 & $\mathrm{H} 2 \mathrm{a}$ & $\mathrm{H} 56$ & 6 & NT & yes & yes \\
\hline 6 & ST-ES6 & $\mathrm{H} 1 \mathrm{~b}$ & U5a & 33 & NT & yes & yes \\
\hline 7 & ST-ES7 & U5a & $\begin{array}{c}\mathrm{H} 1 \mathrm{~b} / \\
\text { U5a (reversed) }\end{array}$ & 33 & NT & yes & yes \\
\hline 8 & ST-ES14 & $\mathrm{D} 4 \mathrm{a}$ & $\mathrm{A} 2 \mathrm{~g}$ & 49 & yes & yes & yes \\
\hline 9 & ST3243-ES1 & $\mathrm{H} 49$ & $\begin{array}{c}\text { B2kl } \\
\text { H49 (reversed) }\end{array}$ & 31 & yes & yes & yes \\
\hline 10 & ST3243-ES2 & $\mathrm{H} 49$ & $\mathrm{~B} 2 \mathrm{k}$ & 31 & yes & yes & yes \\
\hline 11 & NT-ES8 & $\mathrm{X} 2 \mathrm{c}$ & $\begin{array}{c}\mathrm{D} 4 \mathrm{a} / \\
\mathrm{X} 2 \mathrm{c} \text { (reversed) } \\
\end{array}$ & 39 & yes & yes & yes \\
\hline
\end{tabular}

b

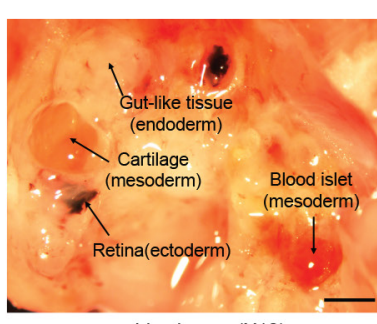

Live image $(\mathrm{X} 10)$
Teratoma tissue

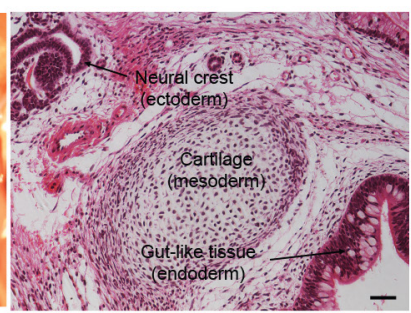

H\&E staining (X200)

Extended Data Figure 5 | Differentiation of ES cells derived from MRT embryos. a, Summary of in vitro and in vivo differentiation of ES cells derived from spindle transfer or SCNT embryos carrying donor mtDNA. Similar to control IVF ES cells, all tested MRT ES cells produced teratoma tumours in vivo and formed neural progenitor cells (NPCs)

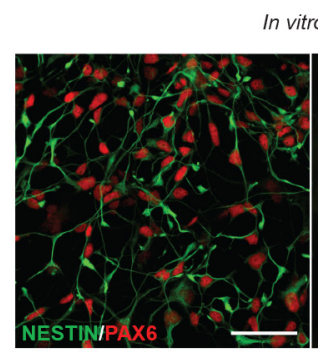

NPCs $(X 400)$ vitro differentiation

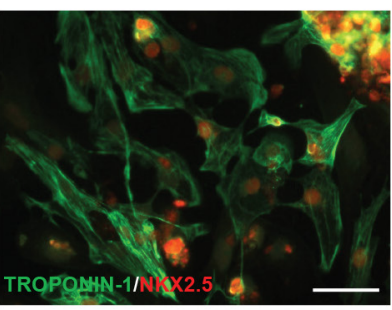

Cardiomyocytes (x400)

and cardiomyocytes in vitro. NT, not tested. $\mathbf{b}$, Histological analysis of differentiated tissues from MRT ES cells. The representative tissues were collected and used for mtDNA carry-over analysis and measurements of mitochondrial function. Scale bars, $1 \mathrm{~mm}$ (live image) and $50 \mu \mathrm{m}$ (haematoxylin and eosin (H\&E) and immunochemistry staining). 


\section{LETTER RESEARCH}

Summary of array CGH in intact and ST blastocysts

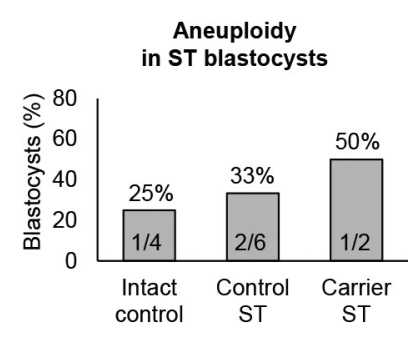

\begin{tabular}{cccccc}
\hline Treatment & $\#$ & $\begin{array}{c}\text { Age of } \\
\text { nuclear donor }(\mathrm{yr})\end{array}$ & Egg donor ID & $\begin{array}{c}\text { aCGH } \\
\text { Results }\end{array}$ & Sex \\
\hline \multirow{4}{*}{ Intact control } & 1 & 34 & hED8 & Abnormal: -21 & Male \\
& 2 & 29 & hED11 & Normal & Male \\
& 3 & 25 & hED4 & Normal & Female \\
& 4 & 25 & hED4 & Normal & Male \\
\hline \multirow{2}{*}{ Control ST } & 1 & 34 & hED8 & Abnormal: $+7,+15$ & Male \\
& 2 & 32 & hED9 & Normal & Male \\
& 3 & 32 & hED9 & Normal & Female \\
& 5 & 32 & hED9 & Normal & Male \\
& 6 & 29 & hED11 & Abnormal: +12 & Male \\
Carrier ST & 1 & 21 & hED1 & Normal & Male \\
\hline & 2 & 36 & cED3 & Abnormal: +9 & Male \\
& 32 & cED4 & Normal & Female \\
\hline
\end{tabular}

b

G-banding analysis of ES cell lines derived from intact and ST blastocysts

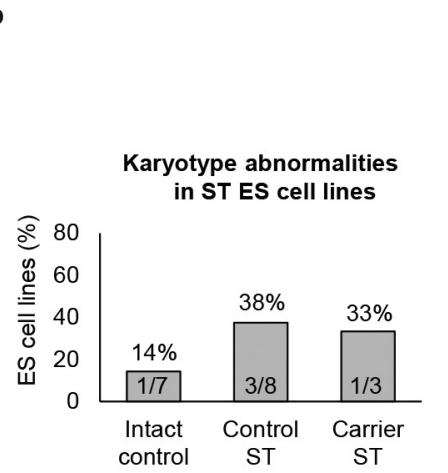

\begin{tabular}{|c|c|c|c|c|c|}
\hline Treatment & \# & $\begin{array}{c}\text { Age of } \\
\text { nuclear donor }(\mathrm{yr})\end{array}$ & $\begin{array}{l}\text { Egg donor } \\
\text { ID }\end{array}$ & ES cell line & Karyotype \\
\hline \multirow{7}{*}{ Intact control } & 1 & 34 & hED8 & ES1 & $46, X X$ \\
\hline & 2 & 29 & hED2 & ES2 & $46, X X$ \\
\hline & 3 & 29 & hED11 & ES3 & $46, X Y$ \\
\hline & 4 & 25 & hED4 & ES4 & $46, X Y$ \\
\hline & 5 & 25 & hED5 & ES5 & $46, X X$ \\
\hline & 6 & 23 & hED3 & ES6 & $46, x x$ \\
\hline & 7 & 23 & hED3 & ES7 & $45, X Y,-21$ \\
\hline \multirow{8}{*}{ Control ST } & 1 & 34 & hED8 & ST-ES5 & $\begin{array}{c}\text { Mosaicism } 47, \mathrm{XX}+10 \\
{[12] / 46, \mathrm{XX}[8]}\end{array}$ \\
\hline & 2 & 34 & hED8 & ST-ES6 & $46, x X$ \\
\hline & 3 & 32 & hED9 & ST-ES3 & $46, X X$ \\
\hline & 4 & 29 & hED2 & ST-ES14 & $46, X Y$ \\
\hline & 5 & 28 & hED6 & ST-ES10 & $45, x$ \\
\hline & 6 & 25 & hED5 & ST-ES7 & $46, X Y$ \\
\hline & 7 & 25 & hED5 & ST-ES8 & $92, X X X X$ \\
\hline & 8 & 25 & hED5 & ST-ES9 & $46, X Y$ \\
\hline \multirow{3}{*}{ Carrier ST } & 1 & 36 & cED3 & 13513 ST-ES & $47, X Y,+9$ \\
\hline & 2 & 32 & cED4 & 3243 ST-ES1 & $46, X X$ \\
\hline & 3 & 32 & cED4 & 3243 ST-ES2 & $46, X Y$ \\
\hline
\end{tabular}

Extended Data Figure 6 | Nuclear genome abnormalities associated with spindle transfer. a, Aneuploidy rate in blastocysts determined by a comparative genome hybridization array was not significantly different in spindle transfer groups compared to controls. b, Karyotype abnormality rate in ES cells determined by G-banding analysis was also comparable among spindle transfer groups $(P>0.05)$. Normal, $46 \mathrm{XX}$ or $46 \mathrm{XY}$. Number inside bars, the number of blastocysts or ES cell lines (abnormal/ total). Simple $\chi^{2}$ tests. 


\section{RESEARCH LETTER}

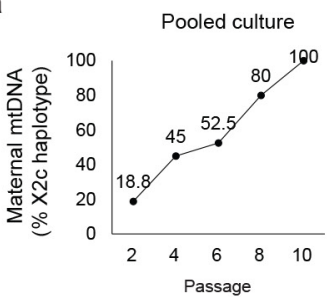

Colony subculture

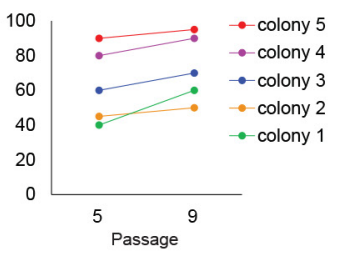

Extended Data Figure 7 | Maternal mtDNA heteroplasmy changes and mitochondrial function. a, Maternal mtDNA (X2c haplotype) heteroplasmy increased during extended in vitro culture and reached homoplasmy in pooled cultures or in individual colony subcultures $(n=1)$. See also Supplementary Table 4 . b, Respiratory chain complex 1

Mitochondrial RC enzyme activity in fibroblasts with various haplotypes

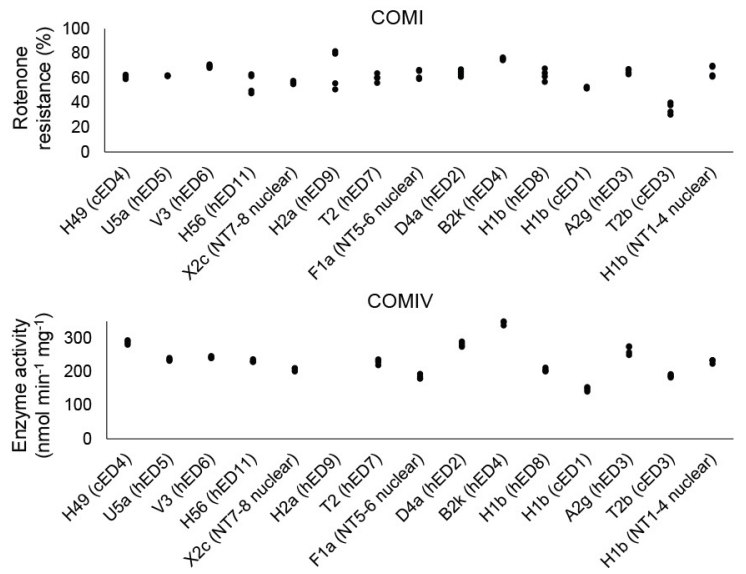

(COM I) and complex 4 (COM IV) enzyme activities were measured in fibroblasts carrying various human mtDNA haplotypes used in this study. No significant differences were noted $(P>0.05)$. One-way ANOVA, $n=4$ technical replicates. Source data file is available for $\mathbf{b}$. 


\section{LETTER RESEARCH}

Extended Data Table 1 | De novo copy number variations (CNVs) in ES cells derived from control and spindle transfer blastocysts

\begin{tabular}{|c|c|c|c|c|c|c|}
\hline Treatment & \# & $\begin{array}{l}\text { ES cell line } \\
\text { ID }\end{array}$ & CNVs & $\begin{array}{c}\text { Chromosome } \\
\text { Location }\end{array}$ & $\begin{array}{c}\text { CNV } \\
\text { chromosome }\end{array}$ & Interpretation \\
\hline \multirow{3}{*}{ Intact control } & 1 & ES1 & $\begin{array}{l}\text { Deletion } \\
\text { (neutral) }\end{array}$ & $15 q 11.2$ & male & $\begin{array}{l}699 \mathrm{~kb} \text { region of chromosome } 15 \text { (15q11.2) } \\
\text { shows low level mosaicism (approximately } \\
10 \%-20 \%) \text { for homozygosity of uncertain } \\
\text { clinical significance. }\end{array}$ \\
\hline & \multirow{2}{*}{2} & \multirow{2}{*}{ ES5 } & $\begin{array}{l}\text { Deletion } \\
\text { (neutral) }\end{array}$ & $15 q 11.2$ & male & $\begin{array}{l}1.1 \mathrm{Mb} \text { region of chromosome } 15 \text { ( } 15 \mathrm{q} 11.2) \\
\text { shows mosaicism for homozygosity of } \\
\text { uncertain clinical significance. }\end{array}$ \\
\hline & & & $\begin{array}{l}\text { Deletion } \\
\text { (neutral) }\end{array}$ & Xp22.33-q28 & male & $\begin{array}{l}\text { Less than } 10 \% \text { of cells of the entire } \\
\text { chromosome } X(X p 22.33-X q 28) \text { of uncertain } \\
\text { clinical significance. }\end{array}$ \\
\hline \multirow{7}{*}{ Control ST } & \multirow{3}{*}{1} & \multirow{3}{*}{ ST-ES5 } & Duplication & 10p15.3-q26.3 & male & Mosaic trisomy 10. \\
\hline & & & $\begin{array}{l}\text { Deletion } \\
\text { (neutral) }\end{array}$ & $15 q 11.2$ & male & $\begin{array}{l}549 \mathrm{~kb} \text { region of chromosome } 15 \text { (15q11.2) } \\
\text { shows mosaicism for homozygosity of } \\
\text { uncertain clinical significance. }\end{array}$ \\
\hline & & & Deletion & Xp22.33-q28 & male & $\begin{array}{l}\text { Monosomy X (Xp22.33-Xq28) of uncertain } \\
\text { clinical significance. }\end{array}$ \\
\hline & 2 & ST-ES6 & None & NA & & NA \\
\hline & 3 & ST-ES7 & None & NA & & NA \\
\hline & 4 & ST-ES9 & None & NA & & NA \\
\hline & 1 & 3243ST-ES1 & None & NA & & NA \\
\hline Carrier ST & 2 & 3243ST-ES2 & $\begin{array}{l}\text { Deletion } \\
\text { (neutral) }\end{array}$ & $15 q 11.2$ & male & $\begin{array}{l}791 \mathrm{~kb} \text { region of chromosome } 15 \text { (15q11.2) } \\
\text { shows mosaicism for homozygosity of } \\
\text { uncertain clinical significance. }\end{array}$ \\
\hline
\end{tabular}

Normal, diploid chromosomal arrangements are identical to original male and female parents. Grey box, shared CNVs among independent cell lines; NA, not applicable. 


\section{RESEARCH LETTER}

Extended Data Table 2 | MRT outcomes for families with pathogenic mtDNA mutations

\begin{tabular}{|c|c|c|c|c|c|c|c|c|c|}
\hline & Family 1 & Family 2 & \multicolumn{2}{|c|}{ Family 3} & Family 4 & \multicolumn{4}{|c|}{ Family 5} \\
\hline $\begin{array}{l}\text { Mitochondrial } \\
\text { disease }\end{array}$ & $\begin{array}{c}\text { Leigh } \\
\text { syndrome }\end{array}$ & $\begin{array}{c}\text { Leigh } \\
\text { syndrome }\end{array}$ & \multicolumn{2}{|c|}{$\begin{array}{c}\text { Leigh } \\
\text { syndrome }\end{array}$} & $\begin{array}{c}\text { Leigh } \\
\text { syndrome }\end{array}$ & \multicolumn{4}{|c|}{ MELAS } \\
\hline $\begin{array}{c}\text { Pathogenic } \\
\text { mtDNA mutation }\end{array}$ & T8993G & T8993G & \multicolumn{2}{|c|}{ G13513A } & No & \multicolumn{4}{|c|}{ A3243G } \\
\hline Age of carrier (yr) & 22 & 23 & \multicolumn{2}{|l|}{36} & 28 & \multicolumn{4}{|c|}{32} \\
\hline $\cos$ & Yes & Yes & \multicolumn{2}{|c|}{ Yes } & Excluded & \multicolumn{4}{|c|}{ Yes } \\
\hline $\begin{array}{l}\text { No. retrieved } \\
\text { oocytes }\end{array}$ & 3 & 5 & \multicolumn{2}{|l|}{4} & NA & \multicolumn{4}{|c|}{11} \\
\hline No. ST oocytes & 2 & Canceled & \multicolumn{2}{|l|}{4} & NA & \multicolumn{4}{|c|}{7} \\
\hline ST blastocysts & 0 & NA & \multicolumn{2}{|l|}{2} & NA & \multicolumn{4}{|c|}{4} \\
\hline Grade at D6 & NA & NA & $5 \mathrm{AA}$ & $5 B B$ & NA & $5 \mathrm{AA}$ & $5 \mathrm{AA}$ & 5BB & $5 \mathrm{CC}$ \\
\hline Aneuploidy & NA & NA & Yes:+9 & NT & NA & NT & No & No & No \\
\hline Sex & NA & NA & M & NA & NA & NA & M & $\mathrm{F}$ & $\mathrm{F}$ \\
\hline mtDNA carryover & NA & NA & $<1 \%$ & NA & NA & NA & $<1 \%$ & $<1 \%$ & $<1 \% *$ \\
\hline
\end{tabular}

Six spindle transfer embryos derived from carrier oocytes reached the blastocyst stage. At least two blastocysts were eligible for transfer. M, male; F, female. NA, not applicable; NT, not tested; D6, blastocysts at day 6 of development. The first number in grade indicates expansion, grade 5 means blastocyst is hatched. The second letter indicates quality of the inner cell mass (ICM), A refers to large ICM of tightly packed cells; B, smaller ICM, loose cells; C, very small ICM. The third letter grades the trophectoderm quality.

*mtDNA in ES cells from this blastocyst reversed to the original maternal haplotype but did not carry the A3243G mutation. 